\title{
Peculiarities of the hind limb musculature in monotremes: an anatomical description and functional approach
}

\begin{abstract}
Petr P. Gambaryan, Alexei A. Aristov*, Joan M. Dixon \& Galina Ye. Zubtsova
ABSTRACT. A thorough description of the hind limb and pelvic muscles of two species of the monotremes is given. The homology of some muscles is discussed. During terrestrial locomotion the platypus shows a movement pattern which is optimal for swimming. Locomotion in the monotremes shows specific mechanical characteristics which differ from those in other tetrapods. Retraction of the femur is one of the main components of propulsive movement in majority of tetrapods; in sphenodontians, crocodiles, squamates it can reach more than $70^{\circ}$, and in therians it is $50-70^{\circ}$. In the monotremes the terrestrial locomotion is executed mainly by pronation of the femur, retraction being no more than $15^{\circ}$. A new hypothesis is proposed on the tuber calcanei evolutionary changes in the tetrapods. Enlargement of the tuber calcanei is usually believed to be strictly connected with the increasing role of flexion in the ankle joint. We consider tuber calcanei primary enlargement to be caused by increasing abduction in the ankle joint which helped the hind foot from slipping sideways during symmetrical-diagonal gaits in animals with widely extended extremities. Tuber calcanei enlargement in mammalian ancestors (as well as the analogous structure enlargement in crocodiles) resulted in increasing load on the lateral toes. In the mammalian evolutionary trend to use asymmetrical gaits, the primary function of the tuber calcanei changed gradually in a way that it could help increasing flexion in the ankle joint, transformation came to an end when mammalian extremities became parasagittal in position. There is an undoubted connection between the tuber calcanei and the fifth metatarsal in Monotremata as well as many advanced cynodonts.
\end{abstract}

KEY WORDS. Monotremata, anatomy, musculature, locomotion.

Petr P. Gambaryan [gambar@PG5237.spb.edu], Zoological Institute, Russian Academy of Sciences, Universitetskaya nab. 1., St. Petersburg 199034 Russia; Joan M. Dixon [Jdixon@mov.vic.gov.au], Museum of Victoria, VictoriaCrescent 71,Abbotsford, Victoria 3067 Australia; Galina Ye.Zubtsova [galina97@hotmail.com],Dalkärrsleden 124, Vällingby S-16271 Sweden.

\section{Особенности мускулатуры задней конечности у монотремат: анатомическое описание и функциональный подход}

\author{
П.П. Гамбарян, А.А. Аристов, Д.М. Диксон, Г.Е. Зубцова
}

РЕЗЮМЕ. Дается подробное описание мускулатуры тазового пояса и задних конечностей двух видов однопроходных, проведена ревизия гомологии ряда мышц. Во время наземной локомоции утконоса обнаруживаются особенности движения, которые оптимальны для плавания. В локомоции однопроходных заметна специфика механики движения, которая отличается от таковой других тетрапод. Ретракция бедра, один из важнейших компонентов для большинства тетрапод, у Spenodontia, Crocodilia, Squamata превышает $70^{\circ}$, а у териевых $50^{\circ}-70^{\circ}$, у однопроходных во время наземной локомоции замещается пронацией, а ретракция бывает не более $15^{\circ}$. Выдвигается новая гипотеза о роли пяточного бугра в эволюционных изменениях у тетрапод. Удлинение пяточного бугра, обычно связывали с усилением флексии голеностопного сустава. Мы считаем, что удлинение пяточного бугра первично было связано с абдукцией в голеностопном суставе, что помогало противостоять скольжению в сторону при симметрично-диагональных походках у животных с широко расставленными конечностями. Пяточный бугор разрастался у предков млекопитающих (так же как аналогичное образование у крокодилов), увеличивая нагрузку на боковые пальцы. При наблюдаемой в эволюции млекопитающих тенденции к использованию асимметричных походок, первичная функция пяточного бугра постепенно менялась в сторону увеличения роли флексии голеностопного сустава, одновременно с переводом конечностей в парасагиттальное положение. Существует несомненная связь между ролью пяточного бугра и пятой плюсневой у однопроходных, так же как и у многих продвинутых цинодонтов.

КЛЮЧЕВЫЕ СЛОВА. Monotremata, анатомия, мускулатура, локомоция.

*Alexei A. Aristov of the Saint-Petersburg Zoological Instiute passed away 02.06.2001 (see obiturary in this volume) 


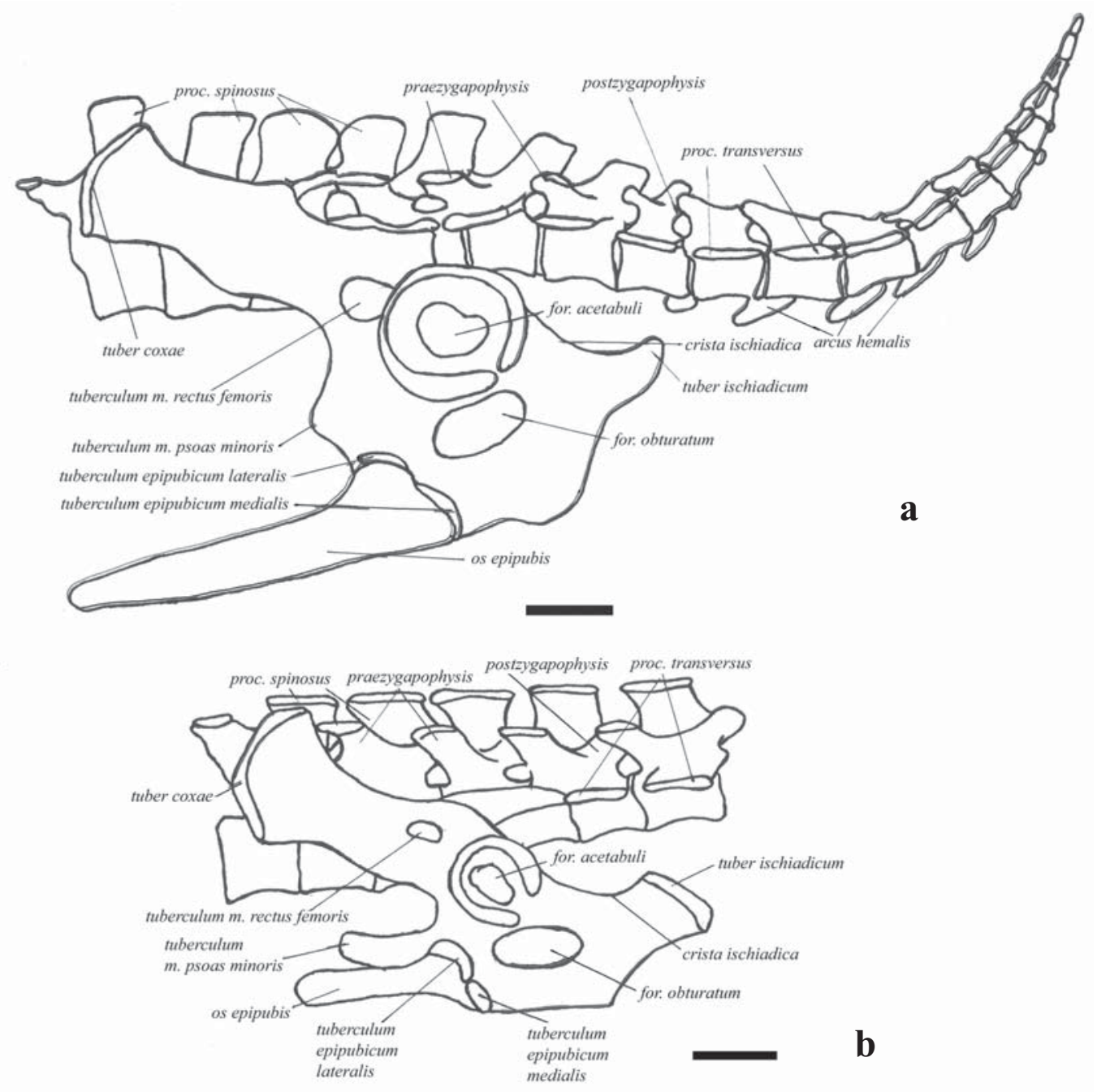

Figure 1. LATERAL VIEW OF THE PELVIC GIRDLE IN TACHYGLOSSUS ACULEATUS (a) AND ORNITHORHYNCHUS ANATINUS (b). Abbreviations: for. - foramen; m. - musculus; proc. - processus. Scale bars $1 \mathrm{~cm}$.

\section{Introduction}

The organs of locomotion of the monotremes have been described on many occasions in terms of anatomy (Meckel, 1826; Mivart, 1866; Coues, 1870; Westling, 1889; Manners-Smith, 1894; Pearson, 1926; Low, 1929; Jouffroy et al., 1971; Walter, 1988). Nevertheless, there is still much uncertainty about homology of some muscles as well as the reasons for their peculiar structure.

The anatomical description of the hind limb and pelvic musculature of two monotreme species, the platypus Ornithorhynchus anatinus (Shaw et Nodder, 1799) and the short-nosed echidna Tachyglossus aculeatus (Shaw et Nodder, 1792) is present below. The specimens investigated are housed in the Zoological Institute, Russian Academy of Sciences in Saint Petersburg (ZIN 85486 and 65487 for T. aculeatus and ZIN 85488 and 85489 for $O$. anatinus). Functional analysis of these groups of muscles has been carried out for the animal's swimming (the platypus), burrowing (the echidna), and terrestrial locomotion (both species). On the basis of muscle topography and functional analysis the questions of homology of the muscles in the monothremes with those of some lower tetrapods and higher mammals are discussed.

In the anatomical nomenclature we followed Schaller (1992), though the hind limb position in monotremes differs significantly from that of domestic animals, for example the cranial surface of the femur in monotremes faces dorsally, and the caudal one ventrally. Some of morphological terms used in the description are given in Figs. 1-5. The hind limb muscles are divided into groups according to Gambaryan $(1972,1974)$, with few changes. For example, three muscles (mm. obturator externus, caudofemoralis, and gemellus) are included herein into the group of short postfemoral muscles. The m. psoas minor is included into the lumbar group, although this muscle does not participate directly in the hind limb movements.

Abbreviations: m. - muscle; mm. — muscles. 

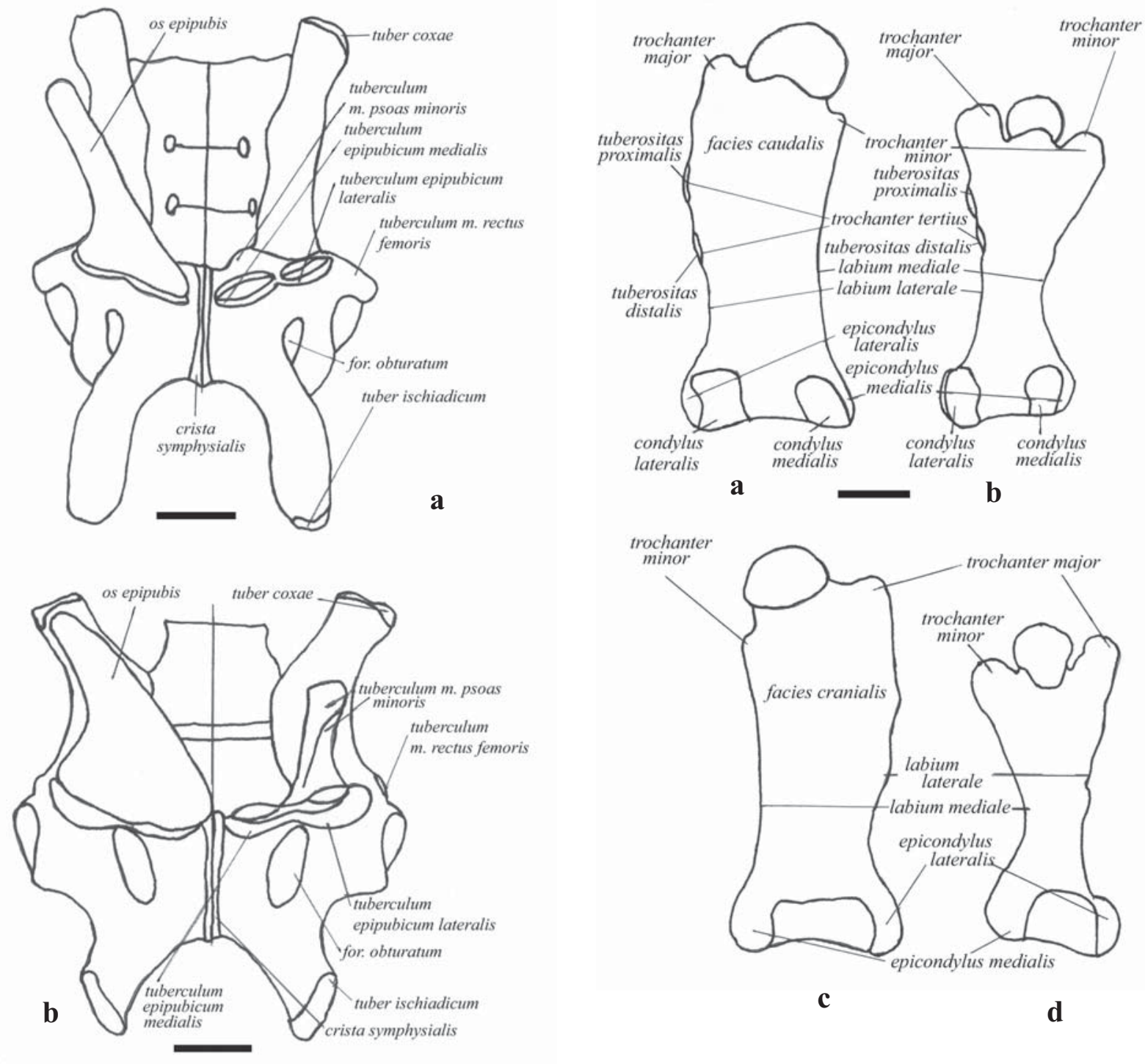

Figure 2. VENTRAL VIEW OF THE PELVIC GIRDLE IN TACHYGLOSSUS ACULEATUS (a) AND ORNITHORHYNCHUS ANATINUS (b). Abbreviations: for. - foramen; m. - musculus. Scale bars $1 \mathrm{~cm}$.

\section{Musculature description}

\section{Gluteus group}

M. gluteus superficialis in Tachyglossus (Figs. 6, 7, $10,11,13)$ arises by an aponeurosis stretched between the neural spines (processi spinosi) of sacral vertebrae II and IV. At the level of the neural spine of the third sacral vertebra it dips below the aponeurosis of $\mathrm{m}$. semitendinosus p.vertebralis to insert on the caudal surface of the distal rugosity of trochanter tertius femoris, distal to the m. caudofemoralis insertion.

In Ornithorhynchus (Figs. 7, 10, 11, 13) this muscle arises by an aponeurosis stretched from the caudal third of

Figure 3. FEMUR IN TACHYGLOSSUS ACULEATUS (a, c) AND ORNITHORHYNCHUS ANATINUS (b, d) IN CAUDAL $(\mathbf{a}, \mathbf{b})$ AND CRANIAL $(\mathbf{c}, \mathbf{d})$ VIEWS. Scale bar 1 $\mathrm{cm}$.

the processus spinosus of vertebra sacralis II to the cranial half of the processus spinosis of vertebra sacralis IV. It arises as well from the praezygapophysis of the last sacral vertebra. The insertion is the same as in Tachyglossus.

M. gluteus medius in Tachyglossus (Figs. 6, 7, 10, $11,13)$ is a complex pinnated muscle in which a proximal, a distal and an intermediate parts can be distinguished. The proximal part arises on the neural spines of the last two vertebrae lumbales and first two vertebrae sacrales, and on the superficial fascia of $\mathrm{m}$. sacrocaudalis dorsalis. It runs to the top of the trochanter major to insert onto it by a strong tendon, some fibres of the intermediate part inserting on the ventral side of the tendon. The intermediate part arises on the tuber coxae 


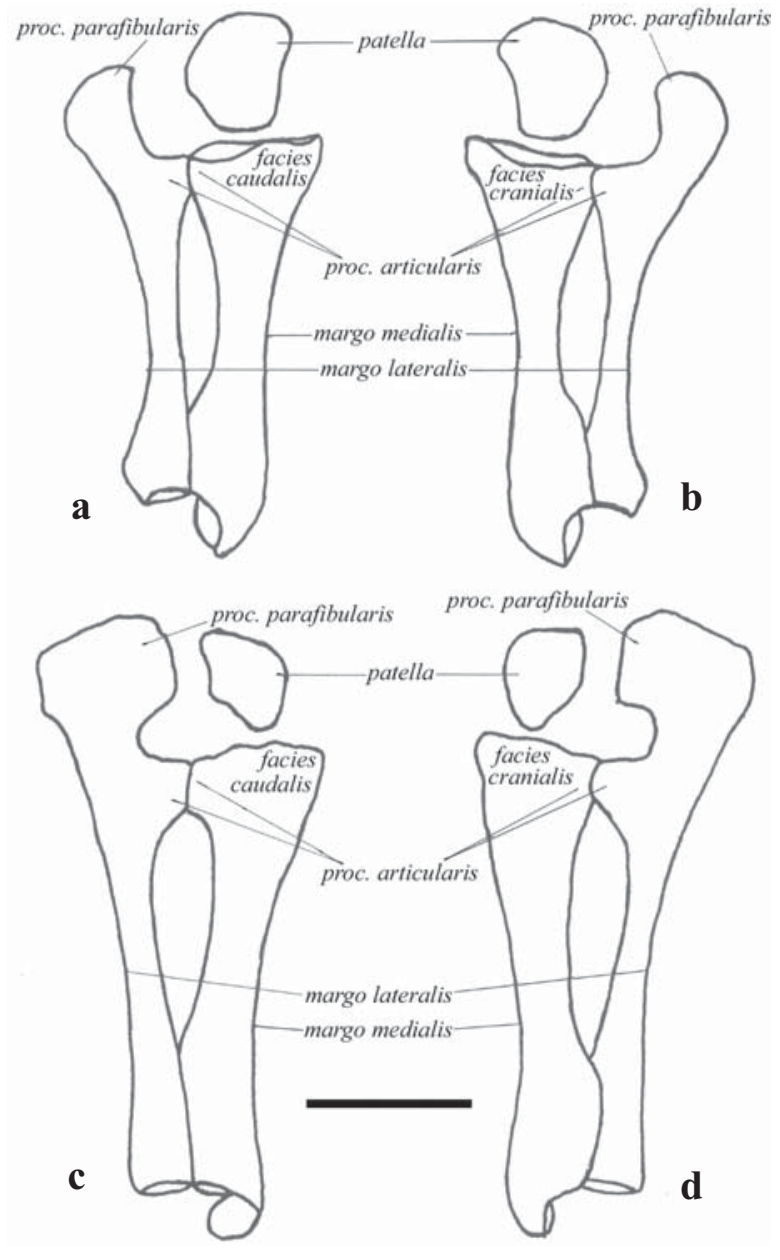

Figure 4. SHIN SKELETON IN TACHYGLOSSUS ACULEATUS (a, b) AND ORNITHORHYNCHUS ANATINUS (c, d) IN CAUDAL $(\mathbf{a}, \mathbf{c})$ AND CRANIAL $(\mathbf{b}, \mathbf{d})$ VIEWS. Abbreviation: proc. - processus. Scale bar $1 \mathrm{~cm}$.

by a strong medial tendon which continues as a superficial aponeurotic sheet. It arises also by muscle fibres on the $\mathrm{m}$. ala ossis ilii and inserts along the trochanter major crest. The distal part arises on both the tendinous origin of the intermediate part and the medial crest of the $\mathrm{m}$. ala ossis ilii. It inserts by a thick aponeurosis on the distal rugosity of the trochanter tertius, i.e. on the medial third of the femur diaphysis.

In Ornithorhynchus (Figs. 6, 7, 10, 11, 13) this muscle is even more clearly differentiated into three parts. The proximal part arises on the dorsal half of the $\mathrm{m}$. ala ossis ilii and on the adjacent outer fascia of $\mathrm{m}$. sacrocaudalis dorsalis. The intermediate and distal parts take their origin from the tendon anchoring on the tuber coxae and from the $\mathrm{m}$. ala ossis ilii crest. These three parts insert as follows: the proximal part on the upper point of the trochanter major, the distal one on the proximal rugosity of the trochanter tertius, and the intermediate one between them.

Corresponding with the different insertion patterns of the distal part of the m. gluteus medius the platypus shows better development of the proximal rugosity of the trochanter tertius, whereas the echidna has the distal rugosity better developed (Fig. 3).

M. gluteus profundus in Tachyglossus (Figs. 10, 11,13 ) is a tiny muscle. It arises very close to the ilium tubercle, the last one being the origin of $\mathrm{m}$. rectus femoris, and surrounds the last muscle from the cranial, dorsal and caudal sides. It runs to insert narrowly on the trochanter major crest deep to the $\mathrm{m}$. gluteus medius.

In Ornithorhynchus the m. gluteus profundus is not present.

It is obvious that due to variability of the gluteus muscles structure different opinions exist concerning terminology of certain muscles of this group. In therians these muscles insert as a rule on the trochanter major and trochanter major crest which is continuous with the labium laterale ossis femoris. The $\mathrm{m}$. gluteus superficialis is a muscle forming the most superficial layer which extends along the labium laterale further downward than any other gluteus muscles. It occurs very often that the $\mathrm{m}$. gluteus superficialis becomes continuous with the $\mathrm{m}$. tensor fasciae latae (Howell, 1926, 1933; Rinker, 1954; Gambaryan, 1960; Klingener, 1964; Kyou-Jouffroy, 1971; and others). In the monotremes the origin of $\mathrm{m}$. gluteus superficialis is much reduced, so this muscle overlays only the most caudal fibres of $\mathrm{m}$. gluteus medius. In all the therians the $\mathrm{m}$. piriformis arises on the ventral surfaces of the sacral vertebrae and runs to insert on the top of the trochanter major deep to the m. gluteus medius. The $\mathrm{m}$. piriformis is absent in the monotremes. Coues (1870) mistakenly described the m. gluteus superficialis under the name of $\mathrm{m}$. piriformis. The proper m. gluteus medius consists of three parts, causing some misunderstandings. The distal part of the muscle was described as m. gluteus minimus (Mivart, 1866; Westling, 1889; Walter, 1988), and all three parts of it were named m. gluteus profundus A, B, C (Low, 1929). The $\mathrm{m}$. gluteus profundus in therians inserts as a rule on the cranial edge of the trochanter major and never extends distally far along the labium laterale ossis femoris, the whole of the muscle being in fact wrapped up in the $\mathrm{m}$. gluteus medius which covers it from both the dorsal and ventral sides. Some investigators (Meckel, 1826; Mivart, 1866; Allen, 1912; Forster, 1918; Walter, 1988) described the $\mathrm{m}$. gluteus profundus as $\mathrm{m}$. gluteus medius which we consider to be in error. The $\mathrm{m}$. semitendinosus p.vertebralis was also mistakenly described as $\mathrm{m}$. gluteus maximus and included in the gluteus group (Low, 1929; Walter, 1988). This muscle is included here in the group of long postfemoral muscles.

\section{Lumbar group}

M. psoas minor origin in Tachyglossus (Figs. 1113 ) is on the ventral side of the bodies of the last two thoracic vertebrae and the first lumbar vertebra, as well as the superficial fascia of $\mathrm{m}$. quadratus lumborum. The muscle is divided into right and left parts by crura diaphragmales anchoring in the middle of the ventral surfaces of the above mentioned vertebrae. The origin of 

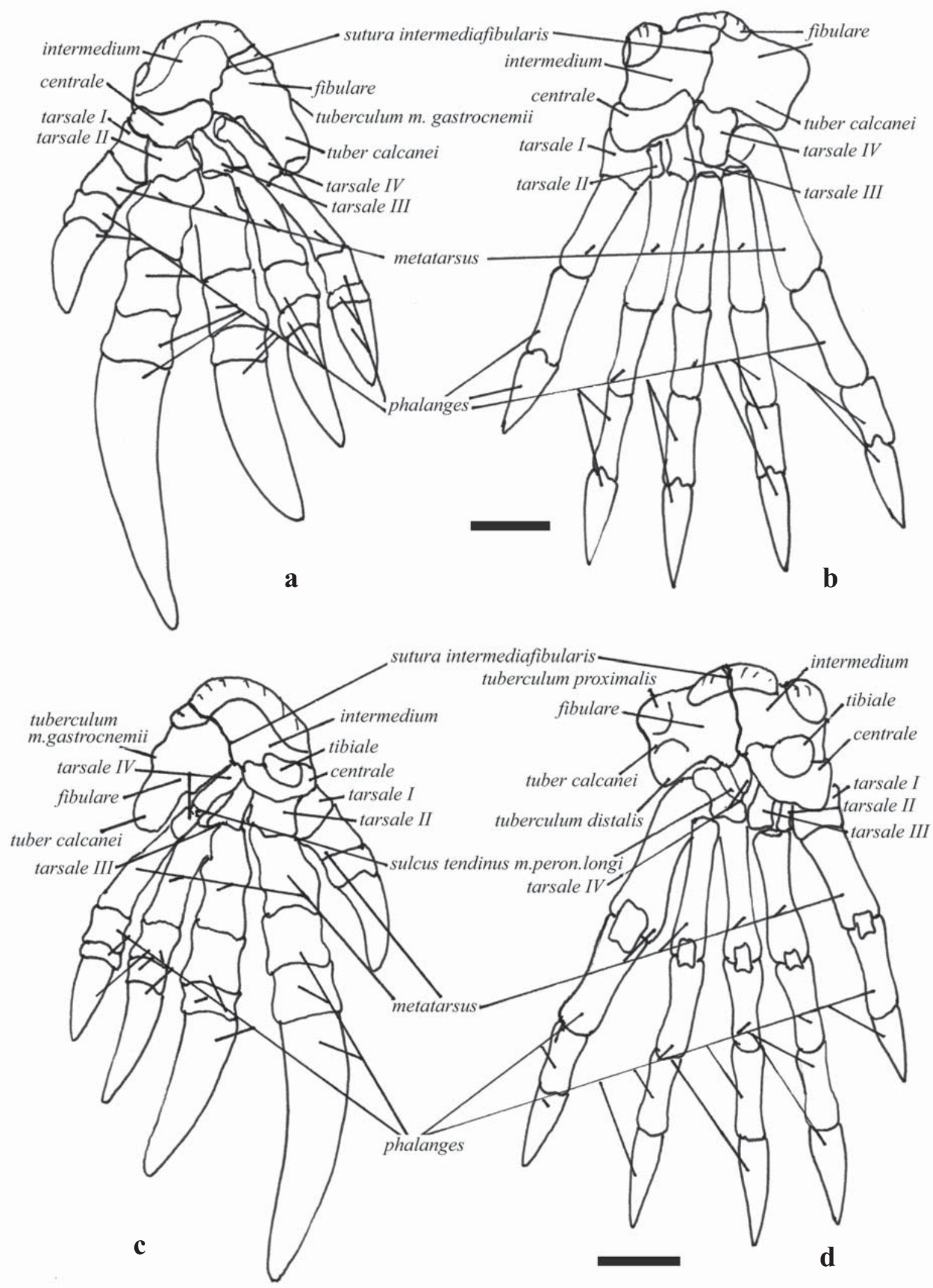

Figure 5. FOOT SKELETON IN TACHYGLOSSUS ACULEATUS (a, c) AND ORNITHORHYNCHUS ANATINUS (b, d) IN DORSAL (a, b) AND VENTRAL (c, d) VIEWS. Abbreviations: m. - musculus; peron. - peroneus. Scale bars $1 \mathrm{~cm}$. 

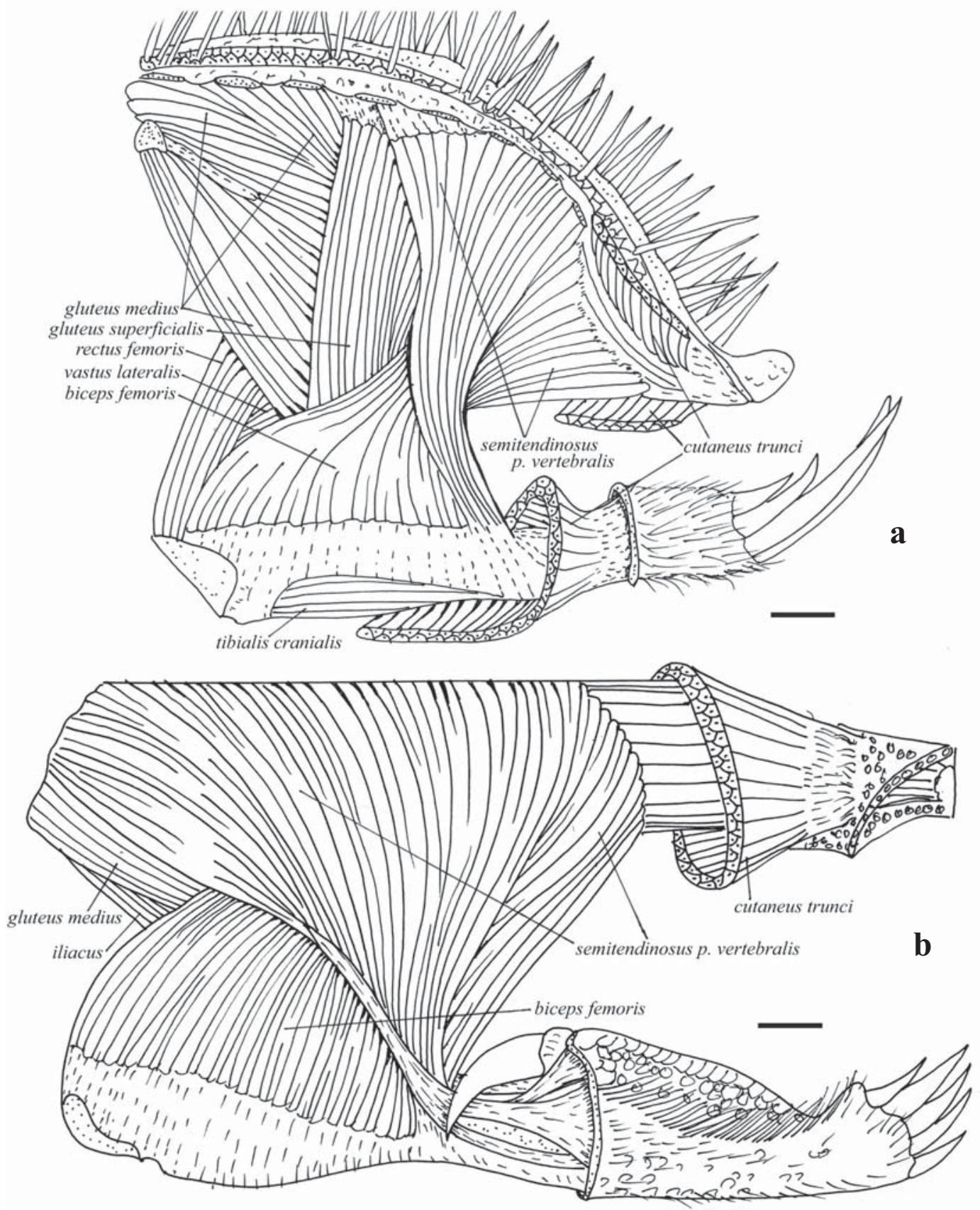

Figure 6. DORSOLATERAL VIEW OF THE SUPERFICIAL MUSCLES OF THE HIND LIMB IN TACHYGLOSSUS ACULEATUS (a) AND ORNITHORHYNCHUS ANATINUS (b). Abbreviation: p. - pars. Scale bars $1 \mathrm{~cm}$.

the right crus diaphragmalis spreads down to the cranial edge of the last lumbar vertebra, that of its mate reaching the caudal edge of the same vertebra. From the level of the first lumbar vertebra the ventral surface of $m$. psoas minor is covered by a superficial aponeurosis which becomes continuous with a strong tendon running to insert on the medial edge of tuberculum psoas minoris.

In Ornithorhynchus the origin of this muscle is on the ventral side of the bodies of the last three thoracic vertebrae and the first lumbar vertebra, as well as the ventral surfaces of the basal parts of the last two ribs. The crus diaphragmalis of the left side anchoring in the middle of the ventral surfaces of the last three thoracic vertebrae displaces the $\mathrm{m}$. psoas minor attachment from there. Its mate takes origin two vertebrae centra caudally. As in Tachyglossus, at the level of the last thoracic vertebra the muscle becomes covered by a tendinous sheet which is continuous with a tendon running to insert 


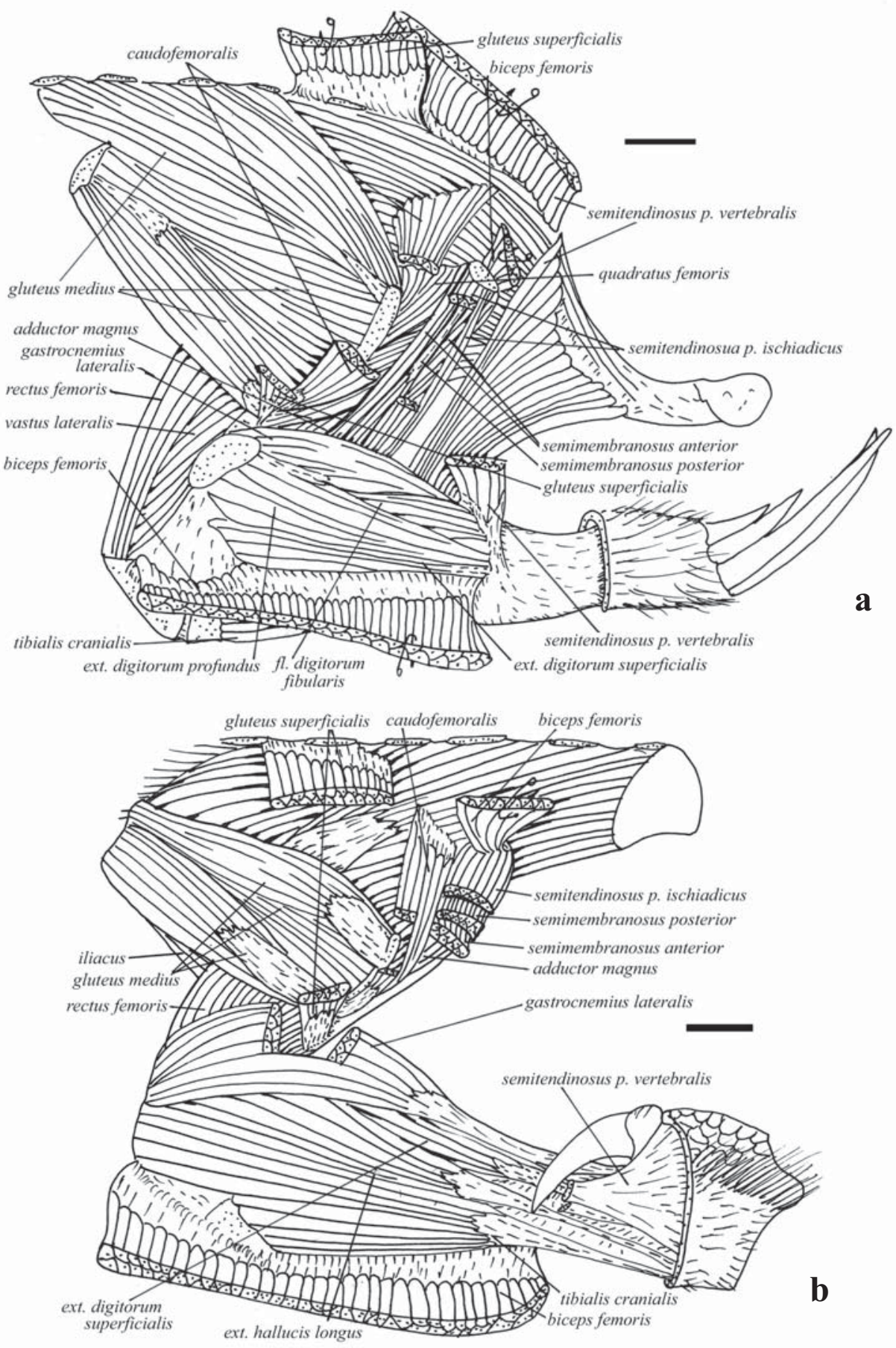

Figure 7. DORSOLATERAL VIEW OF THE DEEP MUSCLES OF THE HIND LIMB IN TACHYGLOSSUS ACULEATUS (a) AND ORNITHORHYNCHUS ANATINUS (b). Abbreviations: ext. — extensor; fl. — flexor; p. — pars. Scale bars $1 \mathrm{~cm}$.

on the craniodorsal ridge of tuberculum psoas minoris. The tubercle is highly prominent, its length being more than half the length of the ilium.

M. iliopsoas is usually divided into the m. psoas major, which originates from the centra of the vertebrae, and $\mathrm{m}$. iliacus arising on the ilium. In therians these two bundles are very often clearly separated proximally, but are fused in the most distal part of the muscle. In Monotremata it is impossible to divide $\mathrm{m}$. iliopsoas into two parts.

In Tachyglossus (Figs. 11-13) it takes its origin on the ventral surfaces of the bodies of the last two lumbar and the first sacral vertebrae, as well as the ventral surface of the ala ossis ilii. The fibres from the vertebrae 

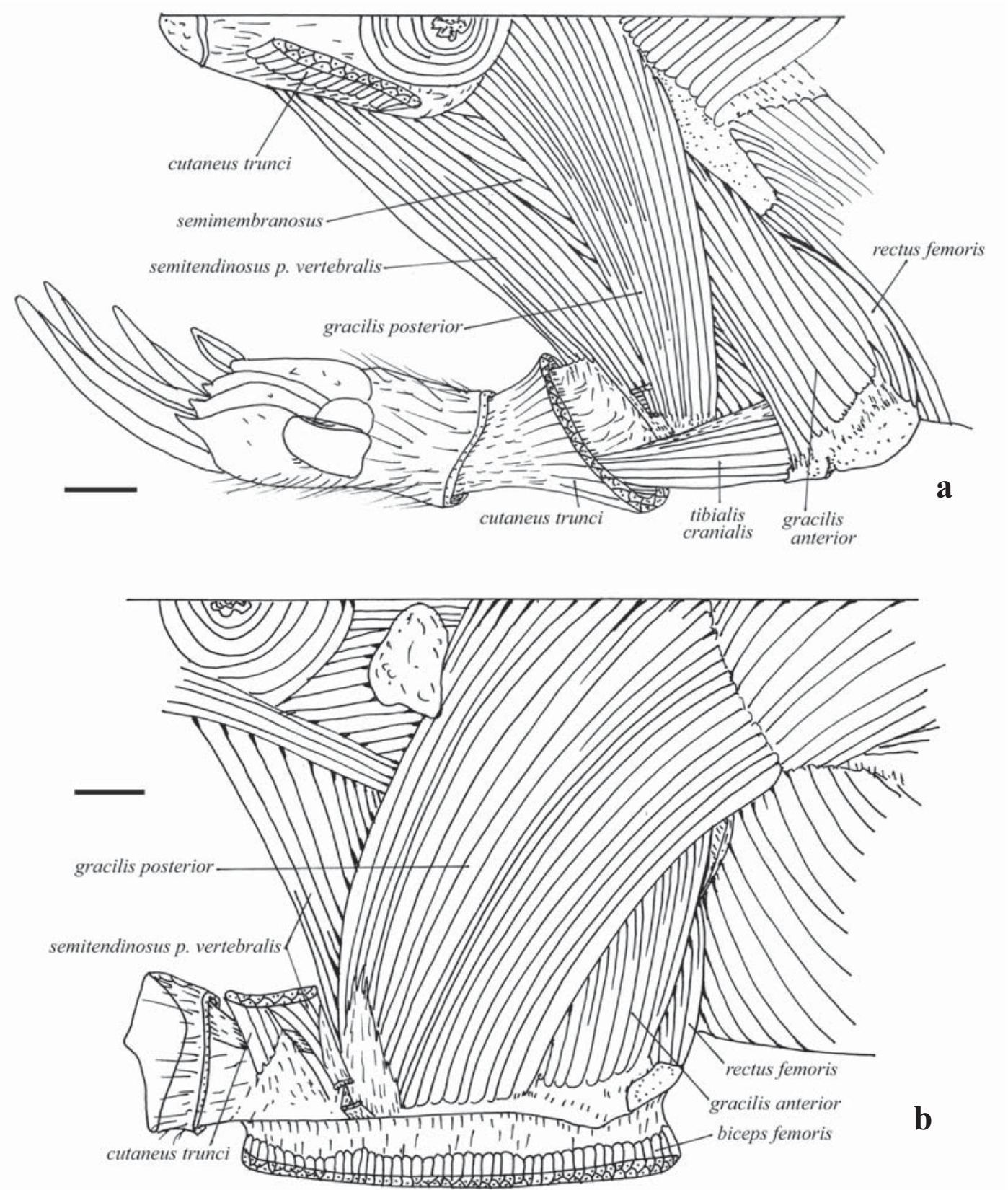

Figure 8. VENTROMEDIAL VIEW OF THE SUPERFICIAL MUSCLES OF THE HIND LIMB IN TACHYGLOSSUS ACULEATUS (a) AND ORNITHORHYNCHUS ANATINUS (b). Abbreviation: p. - pars. Scale bars $1 \mathrm{~cm}$.

bodies insert by aponeurosis along the medial edge of the trochanter minor and the dorsal surface of the labium mediale ossis femoris, the aponeurosis spreading down nearly quarter of the femur length. The fibres from the ala ossis ilii insert on the inner surface of the aponeurosis and along the labium mediale ossis femoris, distal to the previous part, where they cover nearly two-thirds of the femur length.

In Ornithorhynchus (Figs. 6, 10-13) the origin of m. iliopsoas occupies merely half of the ventral surface of the lumbar vertebrae adjacent to the last one, extending from here to the middle of the first sacral vertebra. It includes as well the ventral aspect of the ala ossis ilii. The muscle's insertion occupies the whole of the cranial surface of trochanter minor displacing the origin of $\mathrm{m}$. vastus medialis and extending distally to more than a half of the labium mediale ossis femoris. Such an extensive insertion of this muscle in the monotremes seems to be unique for all the mammals, as it is usually limited to the trochanter minor. 


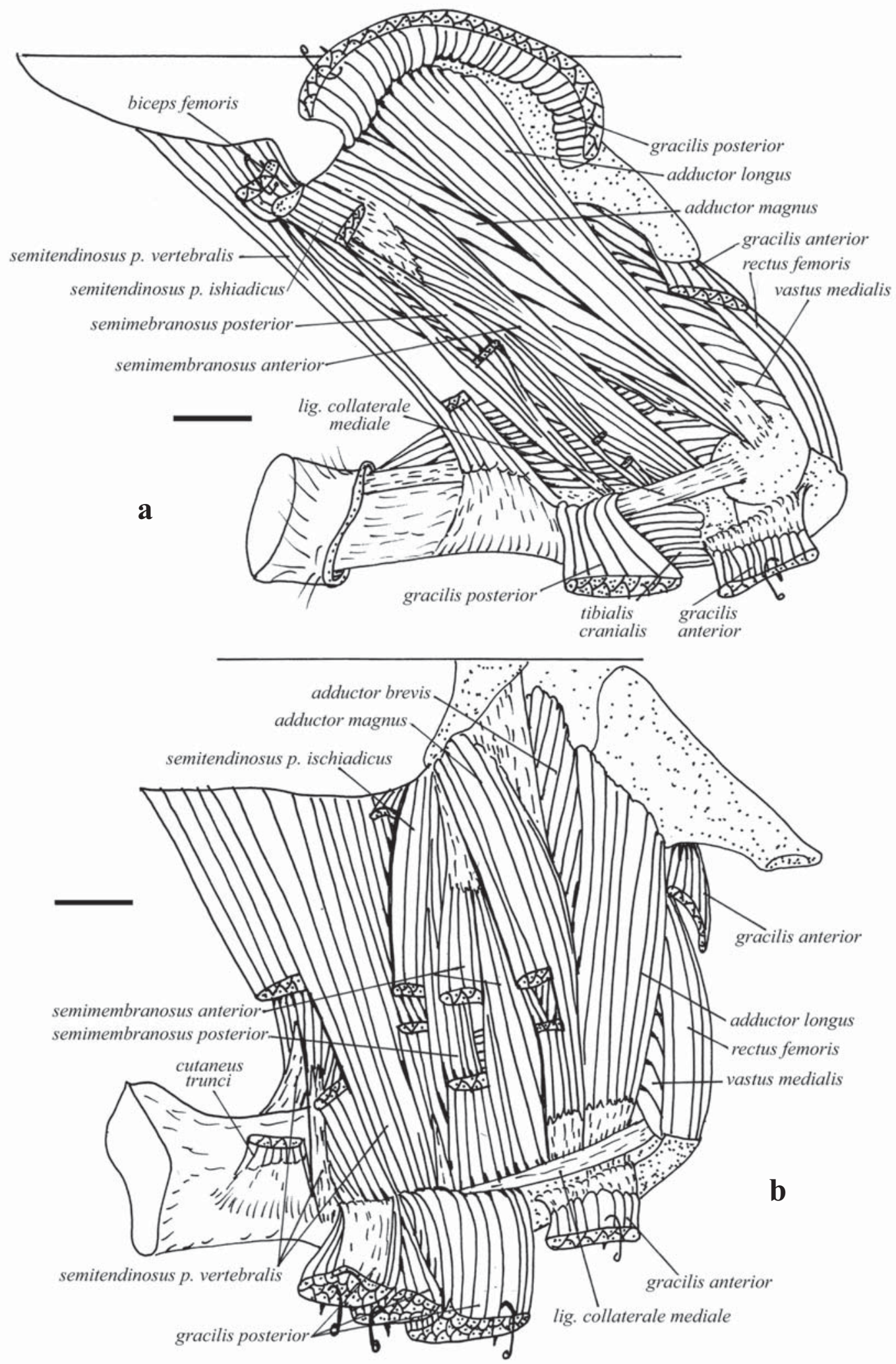

Figure 9. VENTROMEDIAL VIEW OF THE DEEP MUSCLES OF THE HIND LIMB IN TACHYGLOSSUS ACULEATUS (a) AND ORNITHORHYNCHUS ANATINUS (b). Abbreviations: lig. - ligamentum; p. — pars. Scale bars $1 \mathrm{~cm}$. 


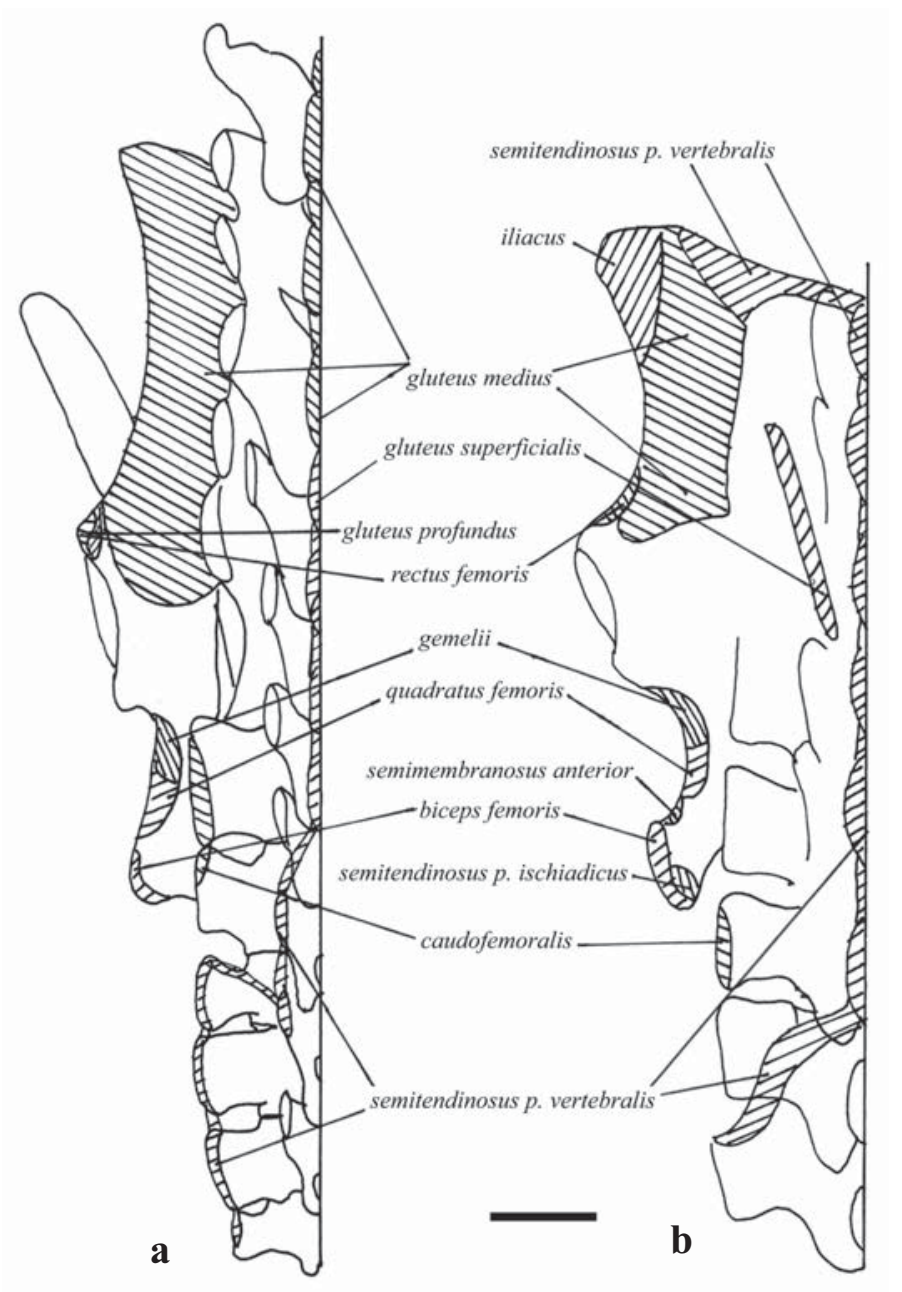

Figure 10. DORSAL VIEW OF THE PELVIC GIRDLE AND SACRUM WITH THE INSERTION SQARES OF MUSCLES OF THE HIND LIMB IN TACHYGLOSSUS ACULEATUS (a) AND ORNITHORHYNCHUS ANATINUS (b). Abbreviation: p. - pars. Scale bar $1 \mathrm{~cm}$.

ventrally to the cranial edge of the proximal half of the os pubis. The muscle inserts by an aponeurosis on the medial third of the labium mediale ossis femoris.

In Ornithorhynchus (Figs. 11-13) the m. pectineus originates by muscle fibres on the dorsomedial surface of the tuberculum $m$. psoas minoris caudal to the $\mathrm{m}$. gracilis anterior origin, then it reaches the base of the tubercle and extends to the os epipubis joint. The last half of the muscle's caudal edge is covered by an aponeurotic sheet which distally becomes a tendinous insertion on the caudal aspect of the labium mediale ossis femoris where it occupies the medial fifth of its length.

M. adductor longus. The origin in Tachyglossus (Figs. 9, 11-13) is located on the os epipubis lateral to that of $\mathrm{m}$. gracilis anterior. It occupies nearly half of the ventral surface of the bone and along the symphysis reaches the proximal third of the caudal edge of the os ischium. The broad insertion of the muscle extends from the medial third of the labium mediale ossis femoris nearly to the distal end of the epicondylus medialis where it runs beneath the ligamentum collaterale mediale.

In Ornithorhynchus (Figs. 9, 11-13) this muscle arises by two distinct parts. The first one originates on the medial edge of a special rugosity of the os pubis close to the pubisepipubis joint, the second part occupying the lateral edge of the rugosity. These parts do not include any of the symphysial branch of the os pubis. The first (medial) bundle, at the level of one-third of its length, is covered by two aponeurotic sheets (mediocaudal and caudal). Finally they become fused to form a single aponeurosis inserting on the distal third of the labium mediale ossis femoris and reaching the distal point of the dorsal surface of the epicondylus medialis. The second (lateral) part of

\section{Short postfemoral group}

M. caudofemoralis in Tachyglossus (Figs. 7, 10 13) arises by an aponeurosis on the superficial fascia of $\mathrm{m}$. sacrocaudalis dorsalis at the level of the transverse spines of the first two caudal vertebrae. It inserts also by aponeurosis on the tuberositas proximalis trochanteris tertius.

In Ornithorhynchus (Figs. 7, 10-13) this muscle originates by fibres on the fascia which lies between the $\mathrm{m}$. sacrocaudales ventralis and $\mathrm{m}$. dorsalis, at the level of the transverse spines of the first caudal vertebra. It inserts by muscle fibres on the caudal aspect of the tuberositas proximalis trochanteris tertius where it occupies a rather large surface.

M. pectineus in Tachyglossus (Figs. 11-13) arises by an aponeurosis on the tuberculum $\mathrm{m}$. psoas minoris lateral to $\mathrm{m}$. gracilis anterior. The attachment curves $\mathrm{m}$. adductor longus inserts by muscle fibres on the mediocaudal tendinous sheet of the medial part.

M. adductor magnus in Tachyglossus (Figs. 9, 1113) arises aponeurotically on the tuber ischiadicus cranial to the $\mathrm{m}$. semimembranosus anterior origin and on the first half of the caudal edge of the os ischium. It lies between the $\mathrm{m}$. gracilis posterior on one side and $\mathrm{mm}$. adductores brevis et longus on the other. The most caudal fibres insert on the caudal surface of the femur. The proximal part of the insertion on the surface of the bone is broad, but narrows distally, the fibres attaching there between the $\mathrm{m}$. gastrocnemius medialis origin and $m$. adductor longus insertion. On the medial epicondyle $\mathrm{m}$. adductor magnus joins the tendinous insertion of $\mathrm{m}$. adductor longus.

In Ornithorhynchus (Figs. 9, 11-13) the muscle arises by a thin aponeurosis which becomes totally fused with the aponeurotic origin of $\mathrm{m}$. semimembranosus anterior 

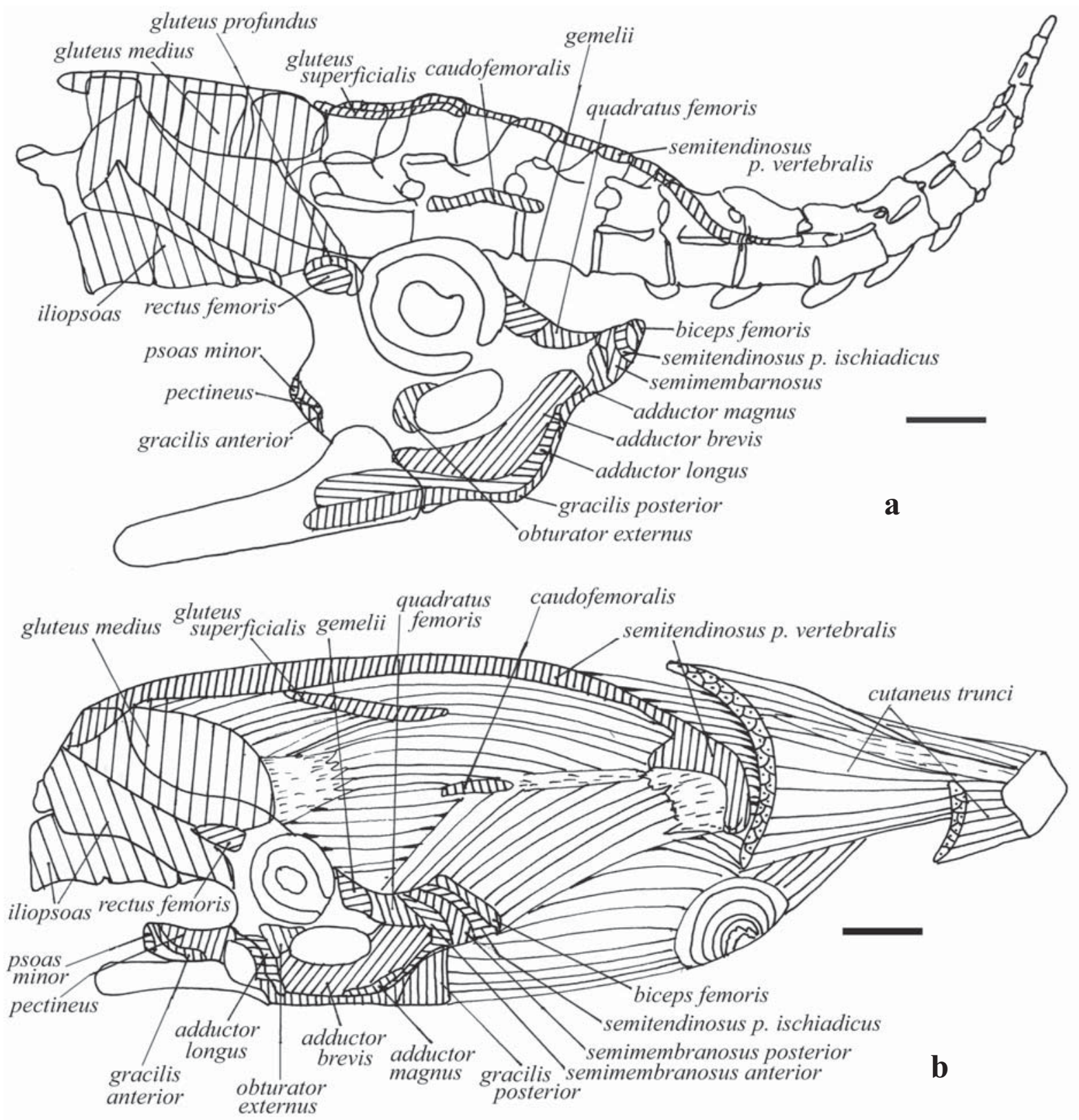

Figure 11. LATERAL VIEW OF THE PELVIC GIRDLE AND SACRUM WITH THE INSERTION SQARES OF MUSCLES OF THE HIND LIMB IN TACHYGLOSSUS ACULEATUS (a) AND ORNITHORHYNCHUS ANATINUS (b). Abbreviation: p. - pars. Scale bars $1 \mathrm{~cm}$.

and a submerged superficial fascia of $m$. adductor brevis. It inserts by a narrow muscle bundle on the caudal surface of the insertion aponeurosis of $m$. pectineus and stretches along the labium mediale ossis femoris to anchor on the ventral surface of the epicondylus medialis. The muscle's insertion is fused with the origin of $\mathrm{m}$. gastrocnemius medialis as well as the caudal part of m. adductor longus. Some fibres of $\mathrm{m}$. adductor magnus insert also on the caudal aponeurotic sheet of the latter muscle.

M. adductor brevis arises in Tachyglossus (Figs. 11-13) on the ventral surfaces of the symphysial branch- es of the os ischium and os pubis, the origin occupying a surface between the other adductors' origin and the foramen obturatum. The muscle inserts by a narrow aponeurosis on a special rugosity between the insertions of $\mathrm{m}$. quadratus femoris and $\mathrm{m}$. obturator externus.

This muscle in Ornithorhynchus (Figs. 11-13) arises on the symphysial branches of the os ischium and os pubis, between the medial edge of the foramen obturatum and the origins of the two adductor muscles described here above. It inserts along the medial edge of the caudal surface of the trochanter major. 

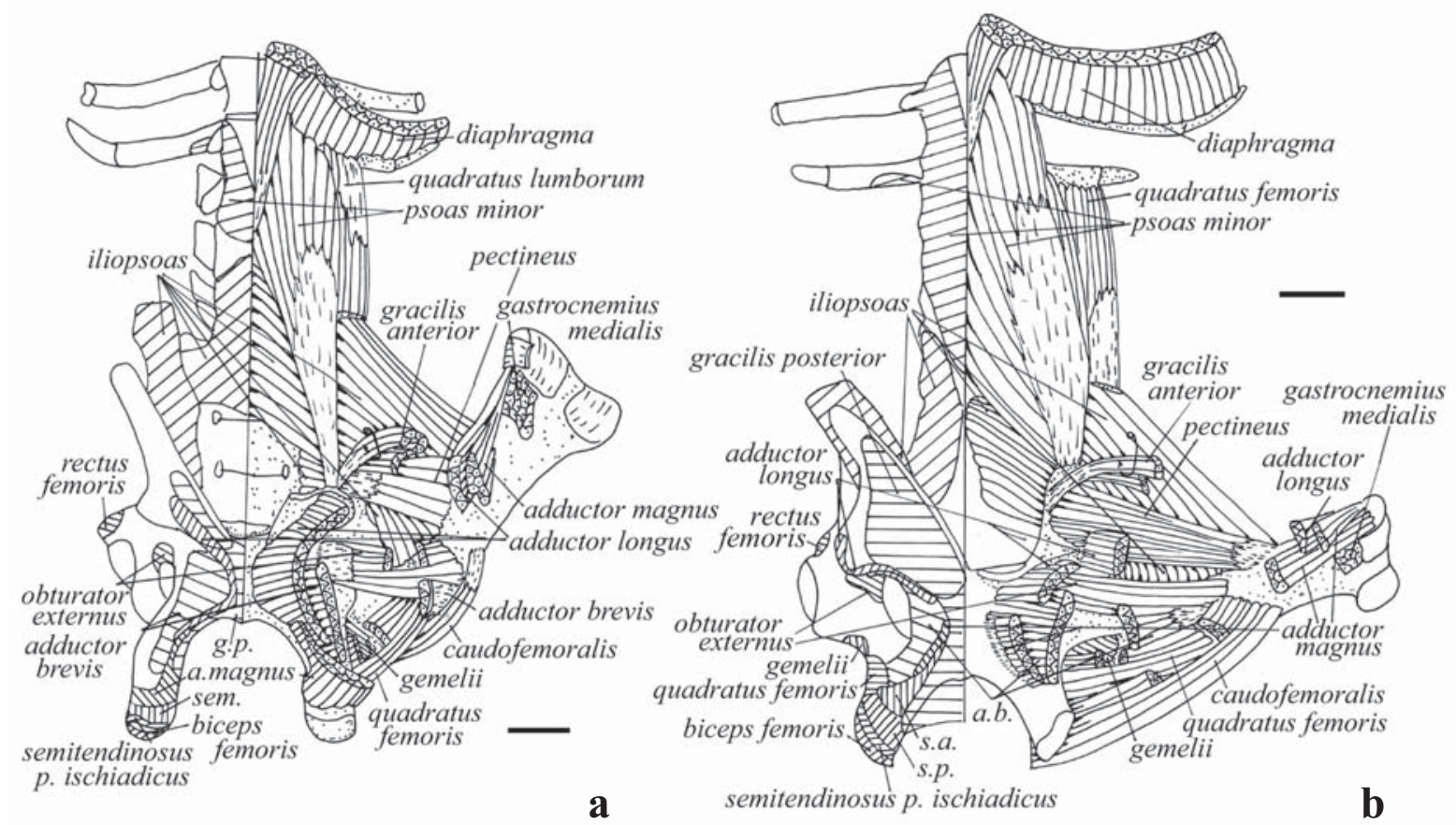

Figure 12. VENTRAL VIEW OF THE PELVIC GIRDLE, SACRUM AND VERTEBRAE WITH THE INSERTION SQARES OF MUSCLES OF THE HIND LIMB IN TACHYGLOSSUS ACULEATUS (a) AND ORNITHORHYNCHUS ANATINUS (b). Abbreviations: a. — adductor; a.b. — adductor brevis; g.p. — gracilis posterior; p. — pars; s.a. semimebranosus anterior; sem. - semimembranosus; s.p. — semimembranosus posterior. Scale bars $1 \mathrm{~cm}$.

There is still much uncertainty about the adductors' nomenclature and therefore their homology. It seems that most of the investigators come to an agreement on the $\mathrm{m}$. adductor longus topography as this muscle originates just close to the $\mathrm{m}$. pectineus. As for the $\mathrm{m}$. adductor magnus and $\mathrm{m}$. adductor brevis, these muscles were very often incorrectly identified. We consider therefore that it is reasonable to distinguish these muscles according to their insertion topography. The $\mathrm{m}$. adductor brevis insertion is the most lateral, it often occupies the lateral edge of crista trochanterica majoris. The insertion of $\mathrm{m}$. adductor magnus spreads as a rule down the caudal surface of the os femur, extending more and more medially and thus reaching the labium mediale ossis femoris or even the medial surface of the epicondylus medialis.

If we take the $\mathrm{m}$. adductor brevis pattern of Ornithorhynchus as an example and then replace the origin of the muscle from the cranial edge of the foramen obturatum onto the tuber ischiadicus, one would get the most lateral $\mathrm{m}$. adductor pattern, which topographically corresponds to that of marsupials, insectivores and rodents (Dobson, 1882; Elftman, 1929; Rinker, 1954; and others). In the men it is only the cranial part of the muscle's origin which can still be found and, besides, the proximal part of $\mathrm{m}$. adductor magnus insertion is situated lateral to that of $\mathrm{m}$. adductor brevis. Tha man probably have such a pattern because of their habitual erect posture as the other primates show another structure of the $\mathrm{m}$. adductor muscles considered here (Kouy-Jouffroy, 1971).

Thus by changing the topographic pattern of $\mathrm{m}$. adductor brevis in Ornithorhynchus one can model the muscle variations in the directions of both marsupials, insectivores, rodents and human beings. It is also probable that $\mathrm{m}$. adductor minimus of the men is homologous with the caudal fibres of $\mathrm{m}$. adductor magnus of other mammals.

M. obturator externus in Tachyglossus (Figs. 11-13) arises on the laterodorsal edge of the foramen obturatum and then the fibres fan out onto the proximal third of the caudal surface of the os femur. It inserts by muscle fibres taking almost rectangular area on the medial part of the femur surface medial to the $\mathrm{m}$. adductor brevis insertion.

In Ornithorhynchus (Figs. 11-13) this muscle also takes origin from the laterodorsal edge of the foramen obturatum caudal to the lateral part of $\mathrm{m}$. adductor longus. It inserts by muscle fibres on the caudal aspect of the trochanter minor proximal to the $\mathrm{m}$. caudofemoralis insertion.

M. quadratus femoris in Tachyglossus (Figs. 1013) originates by muscle fibres on the dorsal surface of the acetabular branch of the os ischium between the $\mathrm{m}$. gemellus and $\mathrm{m}$. semimembranosus and then it runs to insert on the caudal aspect of the upper part of the trochanter major, proximal to the m. adductor brevis.

In Ornithorhynchus (Figs. 11-13) this muscle arises not only on the dorsal surface of the acetabular branch of 

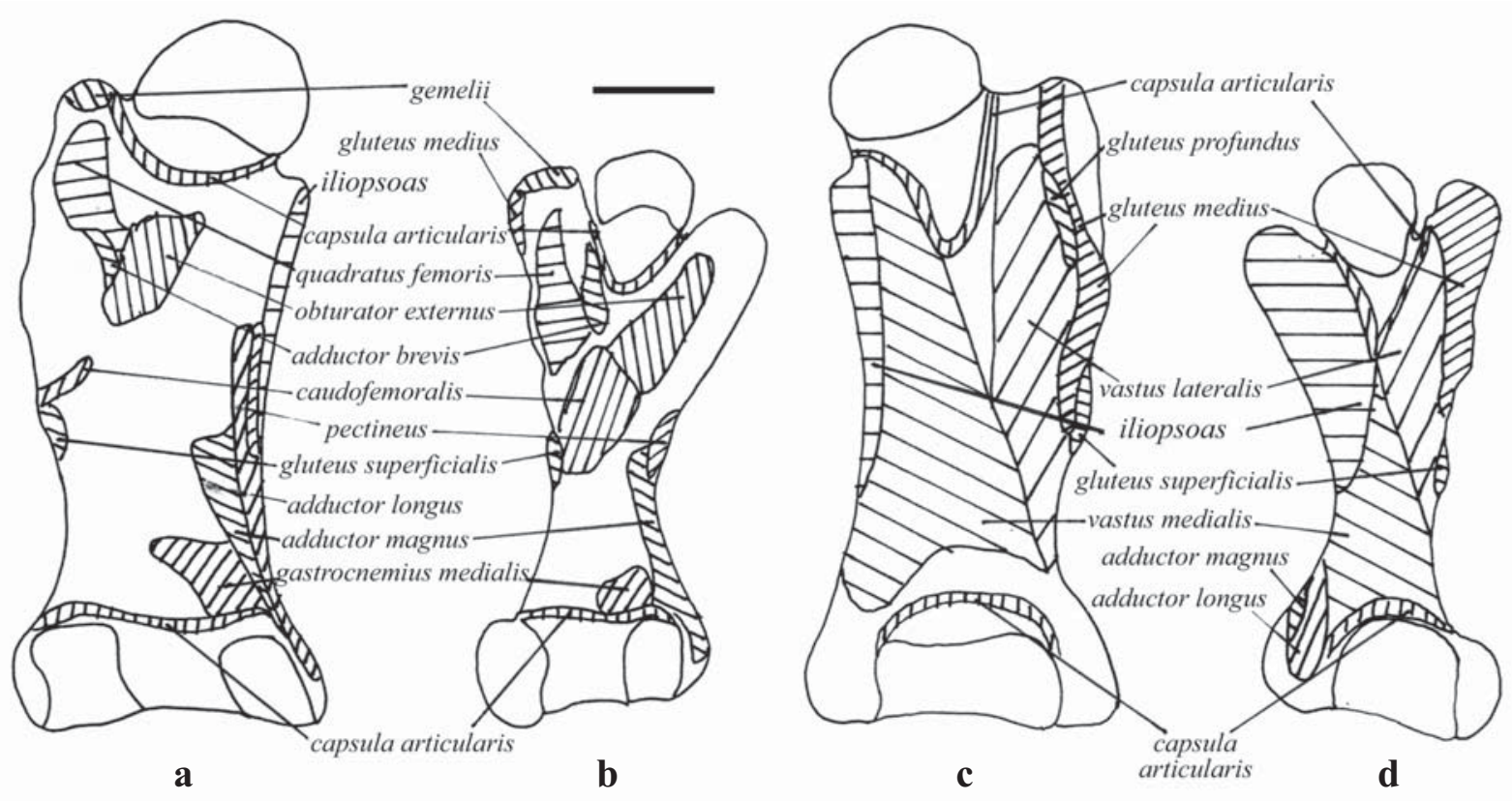

Figure 13. FEMUR WITH THE INSERTION SQUARES OF MUSCLES OF THE HIND LIMB IN TACHYGLOSSUS ACULEATUS (a, c) AND ORNITHORHYNCHUS ANATINUS (b, d) IN CAUDAL (a, b) AND CRANIAL (c, d) VIEWS. Scale bar $1 \mathrm{~cm}$.

the os ischium but comes as well from the ventrolateral aspect of the bone. The origin lies between the $\mathrm{m}$. gemellus and $\mathrm{m}$. semimembranosus anterior. The muscle inserts on the caudal surface of the trochanter major between its rugosities. This muscle's insertion borders on that of $\mathrm{m}$. adductor brevis medially and on that of $\mathrm{m}$. caudofemoralis distally.

M. gemellus (Figs. 10-13) in both species arises on the acetabular branch of the os ischium caudal to the acetabulum and inserts on the caudal aspect of the trochanter major upper part.

Unlike therians, the monotremes lack the fossa trochanterica which in therians serves for the insertion of $\mathrm{m}$. gemelli and $\mathrm{m}$. obturatores.

\section{Long postfemoral group}

M. semitendinosus pars vertebralis in Tachyglossus (Figs. 6-11, 14) arises from the neural spines of the sacral and caudal vertebrae. The origin stretches from the caudal half of the vertebra sacralis I to vertebra caudalis III, then, anchoring on the superficial fascia of $\mathrm{m}$. sacrocaudalis dorsalis, extends to the praezygapophysis of the vertebra caudalis IV and the processi transversi of the vertebrae caudales IV-VI. The cranial bundles arising from the neural spines are separated from the caudal ones, the former inserting on the distal part of the fascia which covers the distal extremity of the shin. The caudal fibres insert on the dorsal surface of this fascia and curve onto its medial side where the proximal part of the insertion becomes continuous with a distinct tendon anchoring distomedial to the distal part of $\mathrm{m}$. gracilis posterior insertion. The cranial fibres' insertion on the fascia of the shin becomes fused with that of $\mathrm{m}$. cutaneus maximus, and they stretch together close to the level of the foot.

The origin of $\mathrm{m}$. semitendinosus pars vertebralis in Ornithorhynchus (Figs. 6-11, 14, 16, 18, 20, 21, 23) stretches to the neural spine of the last lumbar vertebra, the fibres spreading along the fascia erectoris spinae to anchor on the whole of the laterodorsal surface of the tuber coxae. It spreads caudally from the neural spine of the vertebra caudalis III along the superficial fascia of $\mathrm{m}$. sacrocaudalis dorsalis to the praezygapophysis of the vertebra caudalis IV and the processi transversi of the vertebrae caudales III et IV, anchoring along their lateral edges. The origin of the muscle considered spreads also along the superficial fascia of $\mathrm{m}$. sacrocaudalis ventralis to the arcus gemalis between the vertebrae caudales IV and $\mathrm{V}$. The muscle fibres from such an extensive place of origin converge to a strong tendon running to the lateroplantar aspect of the foot (Fig. 18). A tendinous sheet and an aponeurosis split off from the medial surface of this tendon. The tendinous sheet runs to the caudomedial surface of the tendon of $\mathrm{m}$. gracilis posterior, and the aponeurosis inserts on the medial third of the tibia lateral to $\mathrm{m}$. gracilis posterior. The utmost cranial bundles insert lateral to the $\mathrm{m}$. semitendinosus $\mathrm{p}$. ischiadicus. The main tendon becomes considerably broader over the lateral aspect of the foot and then inserts on the dorsolateral edge of the fifth metatarsal and on the dorsomedial edge of the first metatarsal. When the platypus is swimming, the m. semitendinosus exertion makes both lateral and medial metatarsal bones 


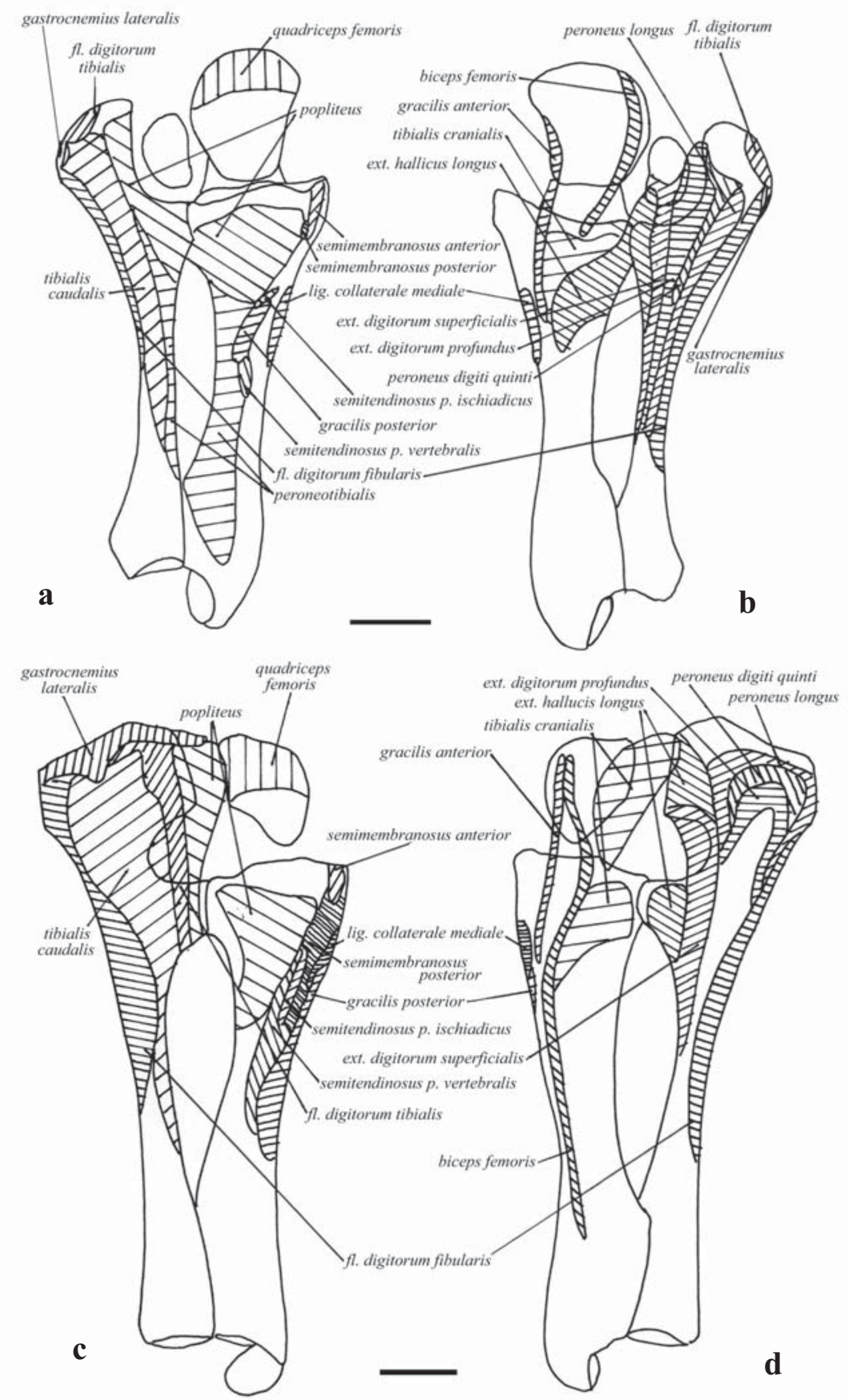

Figure 14. SHIN SKELETON WITH THE INSERTION SQUARES OF MUSCLES OF THE HIND LIMB IN TACHYGLOSSUS ACULEATUS $(\mathbf{a}, \mathbf{b})$ AND ORNITHORHYNCHUS ANATINUS $(\mathbf{c}, \mathbf{d})$ in caudal $(\mathbf{a}, \mathbf{c})$ and cranial $(\mathbf{b}, \mathbf{d})$ views. Abbreviations: ext. — extensor; fl. — flexor; lig. — ligamentum. Scale bars $1 \mathrm{~cm}$.

turn around their longitudinal axes, and the web unfolds automatically under the water pressure.

M. semitendinosus pars ischiadicus in Tachyglossus (Figs. 7, 9, 11, 12, 14) arises together with the m. semimembranosus anterior on the tuber ischiadicus a little cranial to the $\mathrm{m}$. biceps femoris. It originates also on the lateral surface of the aponeurotic sheet of $\mathrm{m}$. semimembranosus anterior, the origin stretching $13 \mathrm{~mm}$ down along the midline and $7 \mathrm{~mm}$ along both the anterior and posterior borders of the sheet. The insertion is deep andlateral to the $\mathrm{m}$. gracilis posterior. The insertions of these two parts of $\mathrm{m}$. semitendonosus are to a certain degree separated by the insertion of $\mathrm{m}$. gracilis posterior. 
M. semitendinosus pars ischiadicus in Ornithorhynchus (Figs. 7, 9, 11-12,14) arises mediocranial to the $\mathrm{m}$. biceps femoris on the tuber ischiadicus surface as well as on the cranial end of the tendinous sheet of $\mathrm{m}$. semimembranosus posterior where it occupies 5-7 $\mathrm{mm}$. It inserts on the caudal surface of the tibia between the m. semimembranosus posterior and $\mathrm{m}$. semitendinosus $\mathrm{p}$. vertebralis.

It is probably by the reason of such an extensive origin of the $\mathrm{m}$. semitendinosus p.vertebralis a certain amount of misunderstanding exists on this question in the literature. Some investigators have described the pars ischiadicus as the whole of the muscle. The pars vertebralis was described as m. gluteus maximus (Meckel, 1826; Mivart, 1866; Manners-Smith, 1894), m. flexor cruris (Appleton, 1928; Low, 1929), or m. crurococcygeus (Pearson, 1926; Jouffroy et al., 1971). In therians, the $\mathrm{m}$. semitendinosus originates as a rule by two bundles which join each other to form a single unit. But in some insectivores the muscle under consideration is divided into two distinct muscles (Dobson, 1882; Gambaryan, 1960), both inserting deeper than the distal part of $\mathrm{m}$. gracilis posterior, thus showing a pattern which is similar to that of Ornithorhynchus described above. In Tachyglossus, as it has been shown, these two parts insert at a rather good distance from each other.

M. biceps femoris in Tachyglossus (Figs. 6, 7, 10 $12,14,15)$ arises from the dorsocaudal edge of the tuber ischiadicus, then runs to the shin to insert by a broad aponeurosis on the tibia. The cranial part of the aponeurosis is distinctly thick and it inserts on the lateral edge of the patella, lateral surface of the ligamentum patellae, and lateral aspect of the tibia crest. The aponeurosis becomes thinner and inserts on fascial sheets separating the long extensors of the foot. It inserts most firmly on the fascia between the $\mathrm{m}$. extensor digitorum profundus and $m$. extensor digitorum superficialis, as well as on the fascia between the latter muscle and $\mathrm{m}$. extensor hallucis longus. The insertion aponeurosis does not curve over the $\mathrm{m}$. ibialis anterior to insert the tibia crest.

In Ornithorhynchus (Figs. 6-8, 10-12, 14) this muscle arises from the dorsocaudal edge of the tuber ischiadicus and inserts by an aponeurosis. The cranial part of this aponeurosis inserts on the lateral edge of the patella and on the outer fascia of $m$. vastus lateralis. Distally, the aponeurosis curves over the $\mathrm{m}$. tibialis anterior to insert the tibia crest, the connection with the fascial sheets laying between the long extensors of the foot being extremely weak. In both species of Monotremata examined no connection could be found between the $\mathrm{m}$. biceps femoris and the Achilles tendon, which is so characteristic of the therians.

M. semimembranosus posterior. The origin of this muscle in Tachyglossus (Figs. 9, 11, 12, 14) is the anterior border of the aponeurosis which is common with the $\mathrm{m}$. semitendinosus $\mathrm{p}$. ischiadicus and arises from the ventral surface of the tuber ischiadicus. The muscle under consideration inserts on the tibia by a thin tendon distolateral to the $\mathrm{m}$. semimembranosus anterior insertion. In one of the specimens examined the muscle from the left side of the body weighed 20 times less than the right side muscle, leading to the condition that it may be totally reduced.

In Ornithorhynchus (Figs. 7, 9, 11, 12, 14) it arises on the tuber ischiadicus cranial to the $\mathrm{m}$. semitendinosus and inserts on the proximal third of the caudal surface of the tibia, close to the medial edge of the bone and between the insertions of the ligamentum collaterale mediale and $\mathrm{m}$. semitendinosus $\mathrm{p}$. ischiadicus, in the proximal part the insertion of the muscle being split by the $\mathrm{m}$. semimembranosus anterior attachment.

M. semimembranosus anterior in Tachyglossus (Figs. $7,9,11,12,14)$ arises on the tendinous sheet of $\mathrm{m}$. semimembranosus posterior close to the distal part of the cranial edge of $\mathrm{m}$. semitendinosus which arises from the same sheet. The muscle inserts caudal and proximal to the ligamentum collaterale mediale not submerging under it.

In Ornithorhynchus (Figs. 7, 9, 11, 12, 14) this muscle arises on the tuber ischiadicus and passes onto the symphysial branch of os pubis situated here lateral to the $\mathrm{m}$. gracilis posterior. It inserts on the very proximal end of the caudal surface of tibia, close to the medial edge of the bone.

M. gracilis posterior in Tachyglossus (Figs. 8, 9, $11,12,14)$ arises on the ventral half of the caudal edge of the os ischium, then its origin along all the symphysis passes onto the proximal third of the os epipubis. The insertion is the second quarter of the crista tibialis, closer to its proximal end and lateral to the ligamentum collaterale mediale.

In Ornithorhynchus (Figs. 8, 9, 11, 12, 14) the m. gracilis posterior is divided into three parts: pars anterior, pars intermedia and pars posterior. Pars anterior arises on the craniomedial edge of the os epipubis, the origin taking two-thirds of the bone's length and more than a half of its width. From the os epipubis the anterior muscle passes onto the cranial third of the symphysis. The origin of pars posterior is the caudal third of the symphysis, the muscle stretching $6 \mathrm{~mm}$ further and becoming fused with the fibres of its mate. The posterior part originates also on the caudal three-fifths of the os ischium. Pars intermedia origin is the remainder of the symphysis (which is not occupied by two previous parts) and the outer fasciae of both anterior and posterior parts of the muscle. The posterior and intermediate parts insert by a tendon which is common both for them and for the $\mathrm{m}$. cutaneus maximus and $\mathrm{m}$. semitendinosus $\mathrm{p}$. vertebralis. The tendon inserts on the tibia to begin with the level of two-thirds of the bone length from its proximal extremity, the length of the insertion being one-tenth of that of the tibia. The insertion on the tibia of the anterior part of the muscle is a narrow strip which starts from a position located at the level of a quarter of the tibia length from its proximal extremity and extends as far as the insertions of the other two parts, the distal end of this strip being lateral to the latter ones. Unlike in Tachyglossus, in the platypus the distal part of the insertion of the pars anterior is medial to the ligamentum collaterale mediale, such a pattern being characteristic 
of mammals. Thus, the $\mathrm{m}$. gracilis pattern in Tachyglossus is considered to be unique among mammals.

M. gracilis anterior in Tachyglossus (Figs. 8, 9, 11, $12,14,15)$ arises on the tuberculum $m$. psoas minoris and the cranial edge of the os pubis. The insertion is on the proximal fifth of the medial edge of the tibia, ligamentum patellae, and the cranial surface of the patella.

In Ornithorhynchus (Figs. 8, 9, 11, 12, 14) the origin is on the tuberculum psoas minoris dorsocaudal to the insertion of the last muscle and cranial to the origin of $\mathrm{m}$. pectineus. Inserting along the medial broadening of the tibia crest it nearly reaches the proximal part of the $\mathrm{m}$. gracilis posterior insertion. Proximally, the muscle inserts on the medial side of the ligamentum patellae and then passes onto the medial edge of the patella.

\section{Extensors of the knee joint}

M. rectus femoris in Tachyglossus (Figs. 6-12) is distinctly separated from the surrounding muscles, namely $\mathrm{m}$. vastus lateralis and $\mathrm{m}$. vastus medialis. It originates from a strong tendon on a special tuberosity of the os ilium very close to the acetabulum, the tendon becoming continuous with a superficial tendinous sheet which covers the proximal third of the muscle. The distal part of the muscle is also overlaid by a tendinous sheet which spreads to the insertion on the patella upper point where the muscle fibres still can be found under the dense tendinous covering.

In Ornithorhynchus (Figs. 7-12) this muscle arises also on the special tuberosity of the os ilium. The distal part of the muscle is fused with the $\mathrm{m}$. vastus lateralis and $\mathrm{m}$. vastus medialis.

M. vastus lateralis in Tachyglossus (Figs. 6, 7, 13) arises on the lateral half of the cranial surface of the femur medial to the $\mathrm{m}$. gluteus medius insertion. The muscle bundle narrows distally to fuse with the $\mathrm{m}$. vastus medialis.

The origin of this muscle inOrnithorhynchus (Fig.13) is on the proximal half of the femur above the m. gluteus medius insertion.

M. vastus medialis in Tachyglossus (Figs. 9, 13) originates on the dorsal aspect of the trochanter minor lateral to the $\mathrm{m}$. iliopsoas insertion. When running distally along the femur it gradually becomes broader. The distal end of the muscle becomes fused with the $\mathrm{m}$. vastus lateralis to insert by fibres on the proximal half of the patella.

The m. vastus medialis in Ornithorhynchus (Figs. 9, 13 ) is totally replaced by the m. iliopsoas from the cranial surface of the proximal half of the femur.

All these three muscles in Ornithorhynchus become fused to insert on the proximal half of the inner surface of the patella.

\section{Long extensors of the hind foot and toes}

It is necessary to comment on some anatomical terms used here as monotremes are characterized by specific limb position. The tibia lateral edge is the edge adjacent to the fibula, i.e. to the fibula's medial edge. The cranial surface of the tibia (which is the attachment place for the muscles of this group) corresponds to that of the fibula. The flattened fibula is characterised by broad cranial and caudal surfaces and narrow medial and lateral edges.

M. tibialis cranialis in Tachyglossus (Figs. 6-9, $14-16,19,20)$ arises on the cranial surface of the tibia distal to the attachment of the knee joint bursa, the origin occupying near a quarter of the bone length. The muscle overlaps more than two-thirds of the medial side of the $\mathrm{m}$. extensor hallucis longus origin. At about one-third of the length along the shin from its distal extremity, the $m$. tibialis cranialis becomes continuous with a flat tendon, which dips under the tendon of $\mathrm{m}$. extensor hallucis longus. These two tendons submerge together under the transverse ligament. The insertion of the $\mathrm{m}$. tibialis cranialis is the dorsomedial aspect of the distal end of the os entcuneiforme (tarsale I). In the species examined the distal part of the tibia is the insertion place for the $\mathrm{m}$. cutaneus maximus which forms here a dense connective tissue fused with the tibia periosteum. It is this thickening which the tendons of the long extensor muscles run through instead of laying, as they normally do, in their synovial sheaths at the distal part of the shin.

In Ornithorhynchus (Figs. 7, 14, 15, 19) this muscle originates from two bundles. The first bundle, which is superficial, arises on the lateral edge of the patella and then from the ligamentum patelloparafibularis passes onto the top of the hooked broadening of the processus parafibularis (=apophysis labelliforme, according to Jouffroy et al., 1971). In some marsupials and multituberculates, it is the parafibula which inserts on the proximal end of the fibula. The topography of the former resembles that of the proximal process of the fibula in the monotremes, and we describe it as processus parafibularis. The second, inferior bundle originates on the proximal extremity of the tibia, occupying about onethird of it from the articulation with the fibula. Over the distal third of the shin the muscle becomes continuous with a flat tendon running close to the tendon of $\mathrm{m}$. extensor hallucis longus and then submerging together with it under the transverse ligament of the shin. The $\mathrm{m}$. tibialis cranialis inserts on the dorsomedial aspect of the distal end of the os entcuneiforme (tarsale I).

M. extensor hallucis longus in Tachyglossus (Figs. $14,15)$ shows a tendency to be split into two bundles. The medial bundle arises on the tibia distal to the origin of $\mathrm{m}$. tibialis cranialis and spreads to the articulation with the fibula. The lateral one arises on the processus articularis fibularis, on the knee joint bursa above the epicondylus lateralis femoris and below the m. extensor digitorum superficialis, and on the medial edge of the fibula extending as far as about one-fifth of its length.

At the level of the proximal third of the shin, the muscle becomes continuous with a thin flat tendon which is overlaid proximally by the broad tendon of $\mathrm{m}$. tibialis cranialis. Distally, the thin tendon comes to the surface and near the distal transverse ligament overlays the broad one to run to the ungual phalanx of the first toe. At the level 


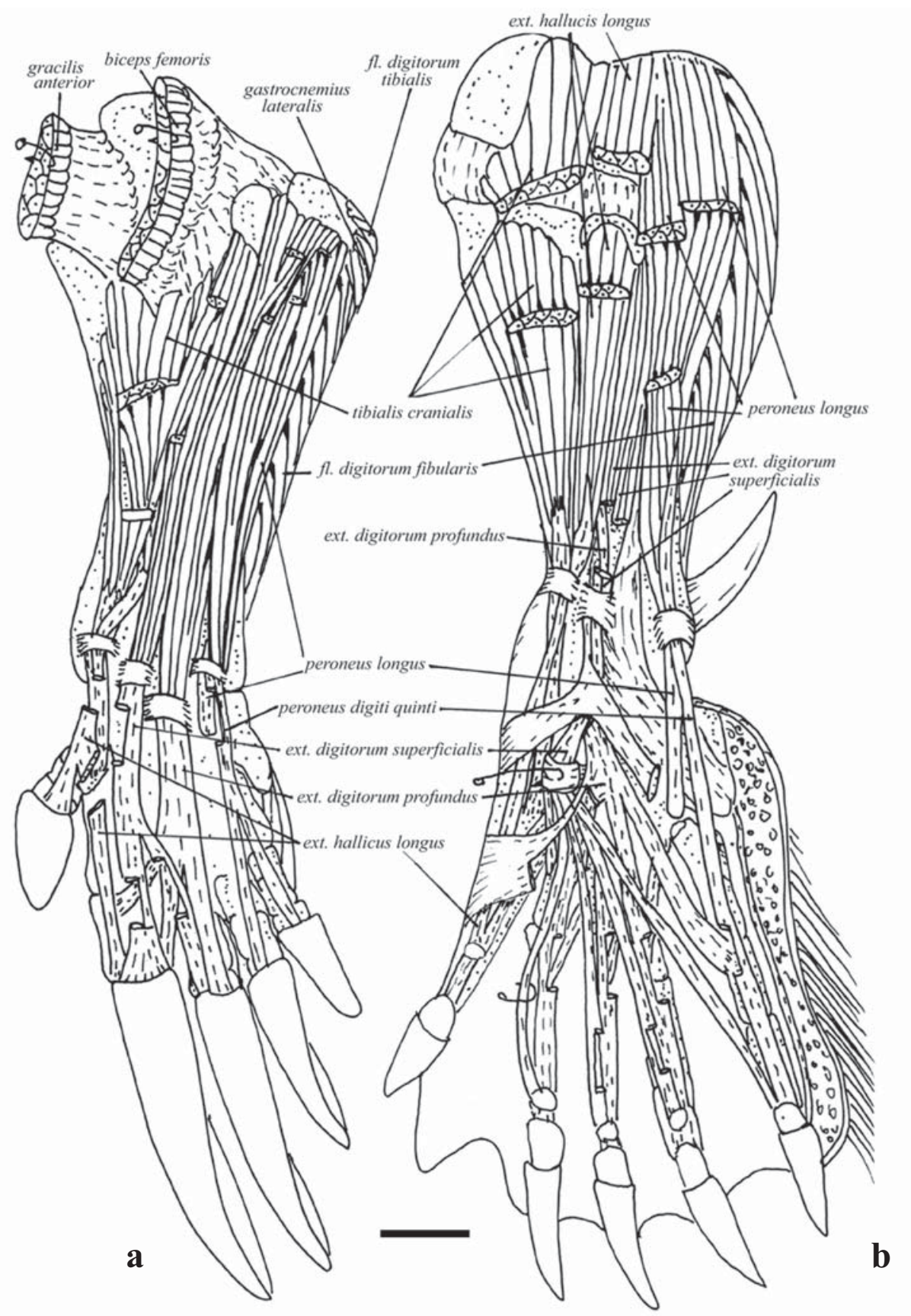

Figure 15. CRANIAL VIEW OF LONG MUSCLES OF THE FOOT IN TACHYGLOSSUS ACULEATUS (a) AND ORNITHORHYNCHUS ANATINUS (b). Abbreviations: ext. - extensor; fl. — flexor. Scale bar $1 \mathrm{~cm}$.

of the first phalanx a tendon splits off from it to insert on the mediodorsal aspect of the ungual phalanx of the second toe. The remainder (lateral) part of the tendon of $\mathrm{m}$. extensor hallucis longus inserts on the same phalanx deeper than the $m$. extensor digitorum superficialis.

In Ornithorhynchus (Figs. 14, 15, 19) this muscle originates by two bundles. The superficial one arises on the processus parafibularis lateral to the $m$. tibialis cranialis and medial to the $\mathrm{m}$. peroneus longus, being anchored on the medial part of the crest between the last two muscles. The deeper bundle's origin is the processus articularis fibularis which bears arched crest. The two bundles become fused at the level of the proximal third of the shin and at the level of the distal third of it this united muscle becomes continued with a tendon which runs close and parallel to the $m$. tibialis cranialis and then overlays it; both submerging under a special transverse ligament. At the foot, the tendon runs along the medial edge of the first metatarsal to insert medially on the ungual phalanx of the first toe. 
M. extensor digitorum superficialis in Tachyglossus (Figs. 14, 15) has its origin on the knee joint bursa above the condylus lateralis ossis femoris and superficial to the $\mathrm{m}$. extensor hallucis longus, then runs distally, taking the proximal two-thirds of the fibula. It becomes continuous with a tendon which runs under the special transverse ligament to insert on the ungual phalanx of the second toe, the tendon splitting off a branch which runs superficial to the tendon of $\mathrm{m}$. extensor digitorum profundus to insert on the third toe.

In Ornithorhynchus (Figs. 14, 15, 19) this muscle is distinctly divided into two bundles which originate independently. The medial bundle's origin is the lateral edge of the arched crest of the processus articularis fibularis as well as the medial edge of the proximal seventh of the fibula. The lateral bundle runs proximally from the arched crest to a place where the m. extensor hallucis longus joins the $\mathrm{m}$. peroneus longus, all the three muscles anchoring on the arched crest of the fibula. Both medial and lateral bundles run to the level of the distal quarter of the shin where each of them becomes continuous with a tendon, these tendons becoming fused at the distal extremity of the shin. At the foot, the common tendon which passes through a special ring-formed ligament, anchored on a tubercle on the mediodorsal aspect of the os naviculare (centrale), splits into five tendons. As this muscle is so distinctly differentiated we artificially continued splitting the tendon into two parts. The medial part itself is split into three branches, one of them running to the second metatarsal and the two others to the ungual phalanges of the second and third toes. The last two branches become completely fused with two tendons which split off from the lateral part. The lateral part sends in all four branches to the four lateral toes, the two medial branches becoming merged with those from the medial part of the tendon. One inserts on the mediodorsal aspect of the second metatarsal, from the middle of the bone to its distal extremity. The other three insert on sesamoid bones on the dorsal surfaces of the second phalanges of the II-IV toes, each of the tendons splitting off branches which one can follow to the ungual phalanges. On the fifth toe the sesamoid bone is absent, so the tendon runs directly to the ungual phalanx. On the toe surfaces these tendons are tightly fused with the joint bursae and tendons of both $\mathrm{m}$. extensor digitorum profundus of the II-IV toes and $\mathrm{m}$. peroneus digiti quinti, the tendons of the last two muscles lying lateral to and below that of the $\mathrm{m}$. extensor digitorum superficialis.

M. extensor digitorum profundus in Tachyglossus (Figs. 14, 15) arises on the knee joint bursa above the condylus lateralis ossis femoris and lateral to the origin of $\mathrm{m}$. extensor digitorum superficialis, it runs along the ligamentum parafibulotibialis to insert the medial edge of the capitum processi parafibulari. Laterally, the muscle is split into two parts, the deeper fibres submerging under the $\mathrm{m}$. peroneus digiti quinti and the superficial ones overlaying it. Distally, the muscle arises on the knee joint bursa, the origin stretching down nearly to one-third of the fibula, where it is situated lateral to the m. extensor digitorum superficialis insertion. The flat muscle reaches the lower part of the shin to run under a special transverse ligament, being here the most superficial of all the extensors. At the foot, it becomes continuous with a tendon which sends three branches to the toes. The first branch runs under the tendon of $\mathrm{m}$. extensor digitorum superficialis to insert on the laterodorsal aspect of the first phalanx of the second toe; the second, broader, one runs also under the tendon of $\mathrm{m}$. extensor digitorum superficialis to insert on the lateral side of the ungual phalanx of the same toe deeper than the $\mathrm{m}$. extensor digitorum superficialis. The third branch, which is the broadest, runs to insert on the inner surface of the tendon of $\mathrm{m}$. extensor digitorum superficialis which, in its turn, runs to the ungual phalanx of the third toe. A tendon running to the fourth toe can sometimes be found (Mivart, 1866; Westling, 1889). A thick bundle of connective tissue from the medial side of the third metatarsal and the dorsal surface of the first phalanx of the third toe attaches to the inner surface of the insertion tendon of $\mathrm{m}$. extensor digitorum profundus to prevent its moving aside from the surface of the third ray.

In Ornithorhynchus (Figs. 14, 15, 19) this muscle arises on the processus parafibularis deep to the $\mathrm{m}$. peroneus digiti quinti and lateral to the $\mathrm{m}$. extensor digitorum superficialis. At the level about one-half the length of the shin the muscle becomes continuous with a tendon which lies in an interosseous space deep to the tendon of $\mathrm{m}$. extensor digitorum superficialis, and run together with it under the ring-formed ligament of the foot which encircles the tendon of $m$. extensor digitorum superficialis. Near the level of the ankle joint two tendinous guys, the lateral and medial, split off from the dorsal surface of the tendon of $\mathrm{m}$. extensor digitorum profundus. They run superficial to all the extensor tendons, the lateral guy inserting in adipose pad of the hind foot, and the medial one coming to the plantar aponeurosis. In Ornithorhynchus there is a pad of adipose tissue at the lateral side of the hind foot, which makes the plantar surface significantly wider. The tendon itself has five flat branches running to toes. The fifth toe branch anchors on the distal extremity of the fifth metatarsal and on the mediodorsal aspect of the proximal extremity of the first phalanx of the fifth toe. Each of the four branches running to the II-IV toes is split, the deep layer inserting on the dorsal surface of the proximal extremity of the first phalanx of the proper toe, and the superficial one stretching to the ungual phalanx having been anchored first on the dorsal sesamoid bone. The tendinous branch of $\mathrm{m}$. extensor digitorum profundus running along the first toe underlies the tendon of the $m$. extensor hallucis longus, the branches running along the four lateral toes underlying the proper tendons of the $\mathrm{m}$. extensor digitorum superficialis. The inner surface of each tendinous branch inserts closely to the periosteum and grows together with the joint bursae of the proper metatarsal and interdigital joints.

M. peroneus digiti quinti in Tachyglossus (Figs. $14,15)$ arises from the processus parafibularis medial to 
the $\mathrm{m}$. peroneus longus and lateral to the $\mathrm{m}$. extensor digitorum profundus, the muscle under consideration overlapping the $\mathrm{m}$. extensor digitorum profundus origin. At about the last third of the shin the muscle becomes continuous with a tendon which runs together with the tendon of $\mathrm{m}$. peroneus longus under the transverse ligament of the shin. At the level of the second phalanx of the fifth toe the tendon of $\mathrm{m}$. peroneus digiti quinti becomes split, a half of it inserting on the lateral surface of the ungual phalanx of the fourth toe, and the other one showing the same insertion pattern on the fifth toe. As the muscle inserts on both the fourth and fifth toes, one should probably consider the $\mathrm{m}$. peroneus digiti quarti to be fused with it.

In Ornithorhynchus (Figs. 14, 15, 19) this muscle arises from the processus parafibularis between the $\mathrm{m}$. peroneus longus and $\mathrm{m}$. extensor digitorum profundus. About the distal third of the shin it becomes continuous with a tendon which runs together with that of the $m$. peroneus longus under the transverse ligament. At the level of the tuber calcanei two strong guys split off from the tendon, one of them inserting in a tendon which lies in a basement of the lateral adipose pad, and the other anchoring on the dorsolateral surface of the proximal extremity of the first phalanx of the fifth toe. The main tendon inserts on the ungual phalanx of the fifth toe. Thus in the platypus the $\mathrm{m}$. peroneus digiti quarti is totally lacking.

In Ornithorhynchus a special tendon of an extensor muscle extends to every ungual phalanx from both medial and lateral sides. The tendon of $\mathrm{m}$. extensor hallucis longus attaches to the first toe from the medial side, as do the tendons of $\mathrm{m}$. extensor digitorum superficialis running to the II-V toes. The $\mathrm{m}$. extensor digitorum profundus extends to the I-IV toes laterally, and the $\mathrm{m}$. peroneus digiti quinti from the lateral side to the fifth toe. In Tachyglossus only the tendon of m. peroneus digiti quinti inserts into the lateral sides of the ungual phalanges of the fourth and fifth toes. The tendons of $\mathrm{m}$. extensor hallucis longus insert on the medial sides of the ungual phalanges of the first and second toes, and the tendon of $\mathrm{m}$. extensor digitorum superficialis reaches the middle of the ungual phalanx of the second toe and the medial side of that of the third toe. The m. extensor digitorum profundus extends to the lateral sides of the ungual phalanges of the second and third toes.

M. peroneus longus in Tachyglossus (Figs. 14, 15, 21,22 ) arises on the lateral half of the distal end of the superior crest of the processus parafibularis between the $\mathrm{m}$. peroneus digiti quinti and $\mathrm{m}$. flexor digitorum fibularis, the origin extending down the fibula for two-thirds of its length. At a point of the distal third of the shin the muscle fibres converge to a tendon which turns through a special groove of the tuber calcanei to the plantar surface of the foot, then the tendon runs transversely from its lateral aspect to the medial to insert distal to all the tarsals on the plantolateral aspect of the first metatarsal.

In Ornithorhynchus (Figs. 14, 15, 19, 21, 22) this muscle originates in three bundles. There is a small thickening on the proximal end of the cranial surface of the fibula, which is an insertion place of superficial aponeuroses of some extensors. In the medial third the thickening curves distally to form a hook, its extension being an origin of an aponeurosis of the medial bundle of $\mathrm{m}$. peroneus longus, where the last one borders the origin of the superficial part of $\mathrm{m}$. extensor hallucis longus. The medial bundle originates along the edge of the hook to the lateral end of the latter one. The lateral and the deeper bundle arises on the lateral edge of processus parafibularis, the origin spreading down the edge to the proximal quarter of the fibula. The most distal fibres border the origin of $\mathrm{m}$. flexor digitorum fibularis, some of them anchoring on the tendinous sheet of the muscle. About the level of the proximal third of the shin all the three bundles mentioned above fuse to form a single muscle which in the distal third becomes continuous with a tendon. This tendon lies together with that of $\mathrm{m}$. peroneus digiti quinti deep to the ligamentum transversum and is situated lateral to the malleolus lateralis and superficial to the ligamentum tibiocalcanei. It then runs through a special groove of the tuber calcanei to the plantar surface of the foot, at the level of the middle parts of all the tarsals, and inserts in the middle of the medioplantar aspect of the first metatarsal.

At the plantar surface of the foot the proximal parts of the synovial sheath of $\mathrm{m}$. peroneus longus fuse with the periosteum of the os naviculare (centrale) and the proximal caput of the os cuboideum (tarsale IV), the distal parts of the synovial sheath anchoring on the os mesocuneiforme, os ectcuneiforme, and os cuboideum (tarsale II, III, and IV) and being the most tightly inserted on the proximal extremity of the fifth metatarsal. It is highly probable that because of this tight insertion the $\mathrm{m}$. peroneus longus has been incorrectly reported to split off a tendon which inserts on the fifth metatarsal (Lewis, 1963, 1964, 1989; Szalay, 1993; and others).

The nomenclature of the long extensors of the hind foot in Monotremata is rather obscure. We consider this animals, as well as most of the therians, having the distinct extensor hallucis longus muscle which originates on the tibia and fibula (in the echidna) or merely on the fibula (in the platypus). In the therians this muscle arises in most cases on the tibia or on the interosseous ligament (Glaesmer, 1910; Abel, 1930; Gambaryan, 1960; Kouy-Jouffroy, 1971; and others). At the very proximal extremity of the shin this muscle of therians, as that of the monotremates, often lies together with the tendon of $\mathrm{m}$. tibialis cranialis deep to the special transverse ligament, which is not connected with the transverse ligaments of the rest of the long extensors. This all suggests the identification of the muscle under consideration given here to be true. The given identification of the peroneus muscle group and, in particular, of the $\mathrm{m}$. peroneus digiti quinti seems also to be without doubt. In the monotremates, as in the therians, the insertion tendon (or two tendons) lies lateral to the remaining long extensors of the toes and, together with the insertion tendon of $\mathrm{m}$. peroneus longus, deep to the special transverse liga- 


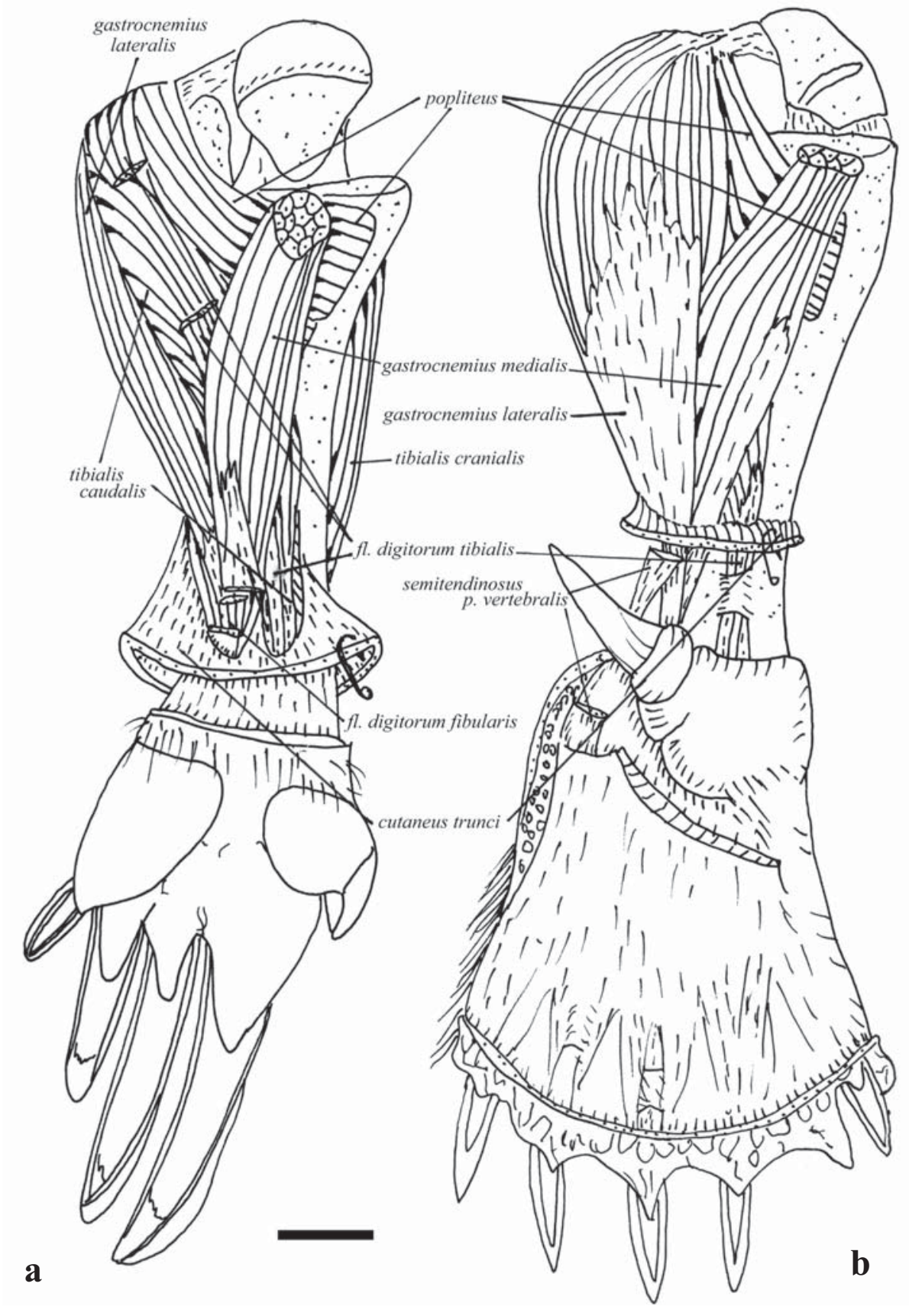

Figure 16. CAUDAL VIEW OF SUPERFICIAL LONG MUSCLES OF THE FOOT IN TACHYGLOSSUS ACULEATUS (a) AND ORNITHORHYNCHUS ANATINUS (b). Abbreviations: fl. - flexor; p. - pars. Scale bar $1 \mathrm{~cm}$.

ment. As for the $\mathrm{m}$. extensor digitorum profundus and $\mathrm{m}$. extensor digitorum superficialis, their homologies with the $\mathrm{m}$. extensor digitorum longus of therian mammals seems to be rather doubtful. The homologization of the first two muscles in the two species here considered is also a complicated problem. Manners-Smith (1894) reported the medial part of $m$. extensor digitorum superficialis in platypus to be distinctly separated from the lateral one. This author described the medial part of the muscle as $\mathrm{m}$. extensor digiti secunda, whereas he considered the lateral part to be a separate muscle which he called the $\mathrm{m}$. extensor digitorum superficialis. Such a misunderstanding leads us to believe that there are two distinct muscles in platypus instead of one. In the specimens investigated here the insertion tendons of these two parts of the muscle run through the mutual ringformed ligament. That is why we consider the two parts as belonging to one single muscle. The question of their 
homologies is still uncertain, i.e. is it the m. extensor digitorum superficialis or m. extensor digitorum profundus which is homologous with the m. extensor digitorum longus of therian mammals.

We should now try to solve a problem on homologies of the above mentioned muscles in the two monotreme species investigated. In the echidna's ankle joint there are four transverse ligaments. There are tendons of the peroneus group muscles below the lateral one. Under the medial ligament there are tendons of $m$. tibialis cranialis and $\mathrm{m}$. hallucis longus, and under the two lying in the middle there are tendons of $\mathrm{m}$. extensor digitorum superficialis and $\mathrm{m}$. extensor digitorum profundus. In the platypus only three of these transverse ligaments could be found. There are the same tendons, as in the echidna, lying deep to the lateral and medial transverse ligaments, and under the single one lying in the middle there are tendons of both two extensors of the toes, so it is quite probable that these two latter muscles of the platypus are homologous with the corresponding two of the echidna. In such a case the only thing in common for these intermediate muscles of the monotremes investigated would be their more or less deep insertion. So, it seems to be quite correct to name them as the $\mathrm{m}$. extensor digitorum superficialis and $\mathrm{m}$. extensor digitorum profundus $(=\mathrm{m}$. extensor superficialis digitorum and $\mathrm{m}$. extensor profundus digitorum, according to MannersSmith, 1894). The m. extensor digitorum profundus is the most superficial muscle of the shin in the echidna whereas in the platypus it is the deepest one. The $\mathrm{m}$. extensor digitorum superficialis consists in the echidna of a single bundle and only one insertion tendon, whereas in the platypus this muscle is composed of two distinct bundles and five insertion tendons. The m. extensor digitorum profundus inserts by a single tendon in the echidna and by five in the platypus.

We cannot agree with the Haines' statement (Haines, 1939) that the $m$. extensor digitorum superficialis is homologous with the $\mathrm{m}$. peronei as this is contrary to the topography of the former muscle. In therians the insertion tendons of the $\mathrm{m}$. peroneus group muscles in the distal part of the shin lie as a matter of fact lateral to the m. malleolus lateralis. The platypus also has two muscles of the peroneus group in this region of the shin. In therian hind foot the insertion tendons of $\mathrm{m}$. peronei lie as a rule deep to the tendons of $\mathrm{m}$. extensor digitorum longus whereas the monotreme's $\mathrm{m}$. extensor digitorum superficialis inserts superficial to the remainders of the tendons of the extensors of the toes. Mivart (1866) considered the muscle named here the m. extensor hallucis longus to be the second bundle of the m. tibialis cranialis ( $=\mathrm{m}$. tibialis anticus), and the muscles we call here $\mathrm{m}$. extensor digitorum superficialis and $\mathrm{m}$. peroneus digiti quinti he described correspondingly as the $\mathrm{m}$. extensor hallucis longus and the second part of $\mathrm{m}$. extensor digitorum longus (which are the mm. extensor digitorum quinti et quarti, according to Westling, 1889).

Such considerable differences in the topography of the long extensors of the hind foot and toes in the
Monotremata could be explained by the following. During platypus swimming it is very important for the hind foot to turn around its longitudinal axis, this function being executed mainly by exertion of the $\mathrm{m}$. peroneus longus; $\mathrm{m}$. tibialis cranialis and $\mathrm{m}$. extensor hallucis longus also taking part in it. These muscles' mass increasing (Table 1) results in enlargement of their attachment areas on the shin surface. So the origins of the $m$. peroneus longus and $\mathrm{m}$. extensor hallucis longus come to a contact and overlay the other muscles' origins. The platypus, unlike the echidna, shows the deepest pattern of the m. extensor digitorum profundus. This could be explained by coming to a contact of functionally the most significant muscles which overlay the less important ones.

\section{Jumping group}

M. gastrocnemius lateralis in Tachyglossus (Figs. $14,16-18,20,23$ ) arises by muscle fibres on the proximal extremities of the lateral aspects of the cranial and caudal surfaces of the processus parafibularis. When reaching the distal end of the shin the muscle becomes continuous with a flat tendon which lies deep to the tendon of m. gastrocnemius medialis. At the level of the calcaneus both these tendons fuse to form a single one which inserts on the tuber calcanei, close to the apex.

In Ornithorhynchus (Figs. 14, 16, 17, 19, 20, 23) this muscle originates also by fibres on a thickening on the caudal surface of the proximal extremity of the processus parafibularis and ligamentum parafibulopatellae. At about third of the thickening of the processus parafibularis there is a distal prominence, the $\mathrm{m}$. gastrocnemius lateralis aponeurosis anchoring here to the lateral edge of the prominence. The aponeurosis becomes continuous with a tendinous sheet which covers the proximal third of the inner surface of the muscle. The outer half of the surface of the muscle is covered by another tendinous sheet which in the distal third becomes continuous with an insertion_tendon. It joins the tendon of $\mathrm{m}$. gastrocnemius medialis to insert on the apex of the tuber calcanei.

The recent therians show the same pattern as Ornithorhynchus, i.e. the insertion tendon of $\mathrm{m}$. gastrocnemius lateralis before joining the Achilles tendon lies superficial to the tendon of $\mathrm{m}$. gastrocnemius medialis. It is obviously because of specific position in Tachyglossus of the insertion tendon of $\mathrm{m}$. gastrocnemius lateralis that this muscle has been described as the $\mathrm{m}$. soleus (Mivart, 1866; Westling, 1889). We support Meckel's opinion (Meckel, 1826) and consider this muscle of the echidna to be named the $\mathrm{m}$. gastrocnemius lateralis, despite its peculiar topography.

M. gastrocnemius medialis in Tachyglossus (Figs. $13,16-18,20,23)$ arises above the medial condyle of the femur; at about the level of the middle of the shin the muscle becomes continuous with a flat tendon which runs to join that of the $\mathrm{m}$. gastrocnemius lateralis. The muscle is also anchored by a thick tendinous guy on the proximal extremity of the tibia. 
Table 1. The relative muscle Weight (a) - the percentage Ratio a single muscle Weight to the Sum WEIGHT OF ALL THE HIND LIMB MUSCLES — AND THE CALCULATED FORCE (b) (IN DYN: 1DYN=10-5 NEWTON) PRODUCED by the hind limb muscles in the Monotremata. AbbreViations: eXt. - eXtensor; fl. - FleXor; P. — pars.

\begin{tabular}{|l|c|c|c|c|l|c|c|c|c|}
\hline \multirow{2}{*}{ Muscles } & \multicolumn{2}{|l|}{ Tachyglossus } & \multicolumn{2}{l}{ Ornithorhynchus } & \multirow{2}{*}{ Muscles } & \multicolumn{2}{l|}{ Tachyglossus } & \multicolumn{2}{l|}{ Ornithorhynchus } \\
\cline { 2 - 7 } & $\mathrm{a}$ & $\mathrm{b}$ & $\mathrm{a}$ & $\mathrm{b}$ & & $\mathrm{a}$ & $\mathrm{b}$ & $\mathrm{a}$ & $\mathrm{b}$ \\
\hline psoas minor & 3.7 & 550 & 5.5 & 580 & gracilis posterior $\mathrm{p}$. anterior & - & - & 3.6 & 200 \\
\hline iliopsoas & 10.6 & 450 & 6.7 & 610 & gracilis posterior $\mathrm{p}$. intermedia & 5.2 & 170 & 4.5 & 250 \\
\hline gluteus superficialis & 3.0 & 110 & 1.8 & 100 & gracilis posterior $\mathrm{p}$. posterior & - & - & 9.4 & 540 \\
\hline gluteus medius & 12.5 & 630 & 4.2 & 600 & popliteus & 1.4 & 110 & 0.6 & 110 \\
\hline gluteus minimus & 0.4 & 40 & - & - & rectus femoris & 5.8 & 270 & 2.7 & 390 \\
\hline caudofemoralis & 1.8 & 70 & 0.6 & 70 & vastus lateralis & 3.8 & 170 & 1.3 & 200 \\
\hline obturator externus & 0.8 & 50 & 0.5 & 60 & vastus medialis & 3.9 & 230 & 0.8 & 130 \\
\hline pectineus & 0.5 & 40 & 0.6 & 80 & gastrocnemius lateralis & 1.2 & 80 & 3.9 & 520 \\
\hline quadratus femoris & 0.9 & 50 & 0.7 & 100 & gastrocnemius medialis & 1.5 & 70 & 0.7 & 90 \\
\hline adductor brevis & 1.5 & 110 & 1.0 & 140 & tibialis cranialis & 0.8 & 40 & 1.5 & 160 \\
\hline adductor magnus & 4.1 & 240 & 1.1 & 140 & ext. digitorum profundus & 1.2 & 30 & 0.3 & 60 \\
\hline adductor longus & 2.8 & 140 & 4.0 & 440 & ext. hallucis longus & 1.3 & 50 & 1.6 & 160 \\
\hline biceps femoris & 5.3 & 140 & 4.5 & 250 & ext. digitorum superficialis & 0.9 & 50 & 0.6 & 70 \\
\hline semitendinosus p. ischiadicus & 2.5 & 80 & 2.8 & 180 & peroneus longus & 0.8 & 50 & 2.1 & 190 \\
\hline semitendinosus p. vertebralis & 4.6 & 90 & 16.3 & 720 & peroneus digiti quinti & 0.7 & 40 & 0.6 & 40 \\
\hline semimembranosus anterior & 5.7 & 210 & 4.0 & 340 & tibialis caudalis & 3.2 & 220 & 1.7 & 260 \\
\hline semimembranosus posterior & 0.8 & 10 & 2.1 & 190 & fl. digitorum tibialis & 1.0 & 50 & 1.0 & 100 \\
\hline gracilis anterior & 3.1 & 140 & 2.3 & 220 & fl. digitorum fibularis & 2.6 & 160 & 3.5 & 490 \\
\hline
\end{tabular}

In Ornithorhynchus (Figs. 13, 16, 17, 20, 23) the muscle origin pattern is the same as in the echidna, some fibres arising on the proximal part of the tibia. It inserts by a tendon which is common for this muscle and the $\mathrm{m}$. gastrocnemius lateralis, the insertion being on the middle of the top of the tuber calcanei, between the tubercles which border a groove for the $\mathrm{m}$. flexor digitorum fibularis to pass.

M. popliteus in Tachyglossus (Figs. 14, 16, 17) arises along the cranial border of the medial aspect of the proximal extremity of the processus parafibularis. The insertion is on the proximal quarter of the medial aspect of the tibia, at a small distance from the insertion places of the $\mathrm{m}$. semimembranosus and $\mathrm{m}$. semitendinosus $\mathrm{p}$. vertebralis.

In Ornithorhynchus (Figs. 14, 16, 17) this muscle arises along the medial edge of the processus parafibularis, the origin being distal to that of the $m$. gastrocnemius lateralis. From here the origin of the m. popliteus extends down along the ligamentum parafibulopatellae to the patella and further distally onto the process articulating with the tibia, lateral to the joint bursa. The insertion is on the caudal aspect of the tibia medial to the m. semimembranosus and $\mathrm{m}$. semitendinosus $\mathrm{p}$. ischiadicus.

M. peroneotibialis could be found only in Tachyglossus (Fig.17). It takes nearly all the interosseous space and is separated from the $\mathrm{m}$. popliteus by popliteal nerve branch. The origin of the muscle extends to the distal quarter of the fibula, the insertion extending to the distal sixth of the tibia. Two last muscles were added into this group artificially.

\section{Long flexors of the hind foot and toes}

We think necessary to give a description of the aponeurosis plantaris first.

The aponeurosis in Tachyglossus (Figs. 17, 18) is split into two layers. The superficial one anchors distal to the $\mathrm{m}$. peroneotibialis on the caudal surfaces of the distal extremities of the fibula and tibia. In the proximal part of the foot it is thickened transversely and anchors along the medial edge of the first toe, to the ungual phalanx, and on the lateroplantar edge of the tuber calcanei. From the distal part of the thickening to the lateral and medial edges of the three middle toes and to the medial side of the fifth toe there are guys of connective tissue running which are getting thicker above the synovial sheaths of the insertion tendons of $\mathrm{m}$. flexor digitorum fibularis. The deep layer of the aponeurosis plantaris anchors on the lateral edge of the tibia and the medial edge of the tuber calcanei to form a transverse arch, the inner surface of it merging with the tendon of $\mathrm{m}$. flexor digitorum fibularis.

In Ornithorhynchus (Fig. 18) the proximal part of the single-layered aponeurosis plantaris looks as if it were a continuation of the $\mathrm{m}$. semitendinosus $\mathrm{p}$. vertebralis. The most robust part of the aponeurosis reaches 


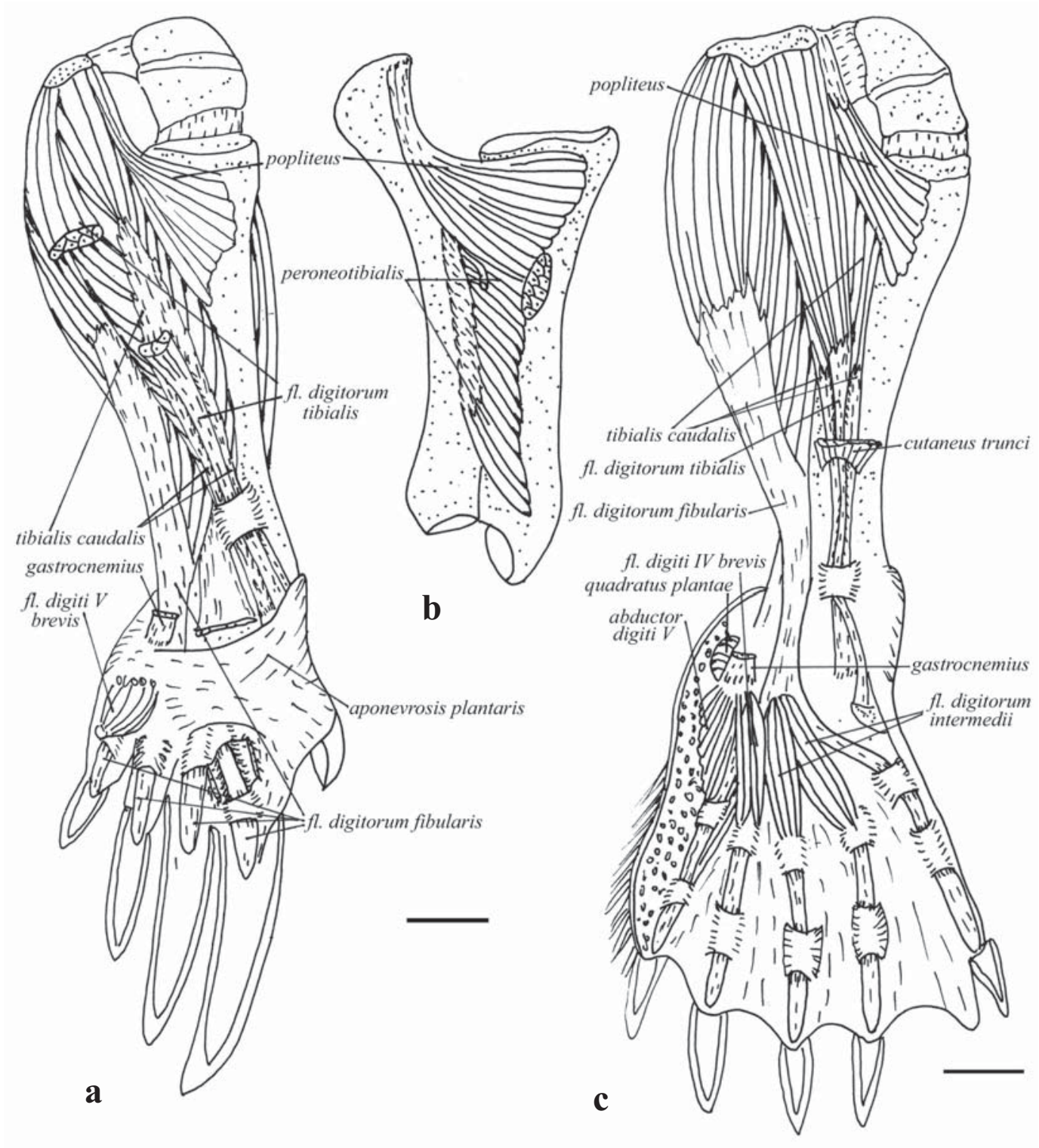

Figure 17. CAUDAL VIEW OF DEEP LONG MUSCLES OF THE FOOT IN TACHYGLOSSUS ACULEATUS (a, b) AND ORNITHORHYNCHUS ANATINUS (c). a, c — the second layer; b - the third layer. Abbreviation: fl. — flexor. Scale bars $1 \mathrm{~cm}$.

the medial edge of the first metatarsal to insert on it. From the distal end of the tendon of $\mathrm{m}$. semitendinosus p. vertebralis there are some guys running which are formed out of loose connective tissue to be easily extended, with adipose cells included. In the intertarsal and interdigital areas these guys are split to form vertical septa stretched vertically between the inner surfaces of the dorsal and plantar skin cover of the foot. From the lateral edge of the tendon of $\mathrm{m}$. semitendinosus $\mathrm{p}$. vertebralis one more (inner) plate of the aponeurosis plantaris splits off which inserts on the distal tubercle of the plantar surface of the tuber calcanei. On the distal end of the inner aponeurotic plate the superficial part of the $\mathrm{m}$. abductor digiti quinti brevis and $\mathrm{m}$. quadratus plantae have been inserted. Superficial to these two muscles there are two guys of connective tissue running to the base of the lateral adipose pad of the hind foot. One of the gyus stretches over the pad to insert in a marginal part of the skin cover, the other, distal one, inserting in the middle part of the adipose pad. Here a plate of connective tissue is formed to run along the lateral edge of the fifth metatarsal and the phalanges of the fifth toe. The plate's insertion is on the distal eminence of the tuber calcanei and the distal extremity of the second phalanx of the fifth toe. From the lateral side superficial to the plate the adipose pad is situated which makes the hind foot broader.

M. tibialis caudalis in Tachyglossus (Figs. 14, 16$18,20-22$ ) arises both on the caudal surface of the proximal end of the processus parafibularis, lateral to 


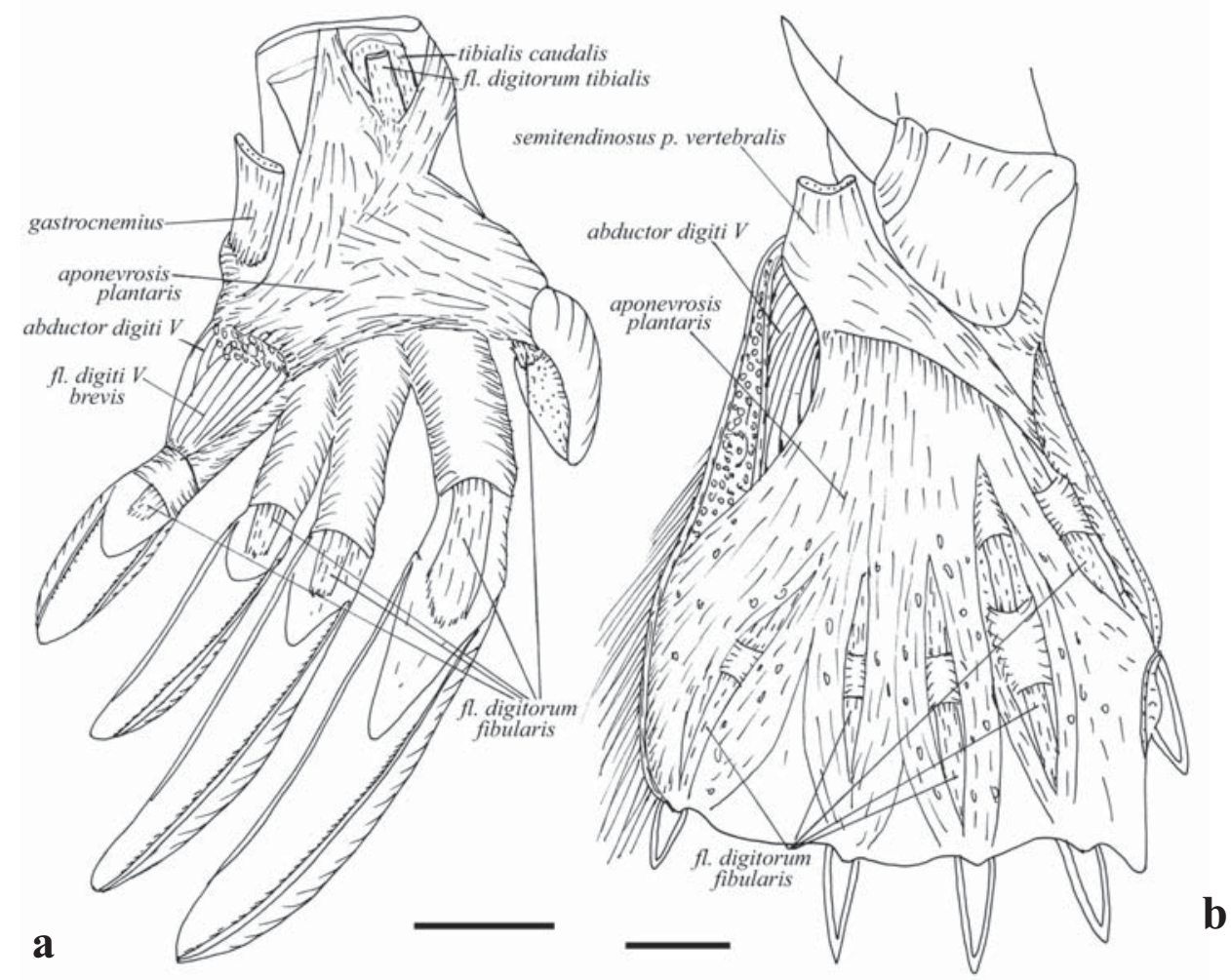

Figure 18. APONEUROSIS PLANTARIS IN TACHYGLOSSUS ACULEATUS (a) AND ORNITHORHYNCHUS ANAT$\operatorname{INUS}(\mathbf{b})$. Abbreviation: fl. - flexor. Scale bars $1 \mathrm{~cm}$.

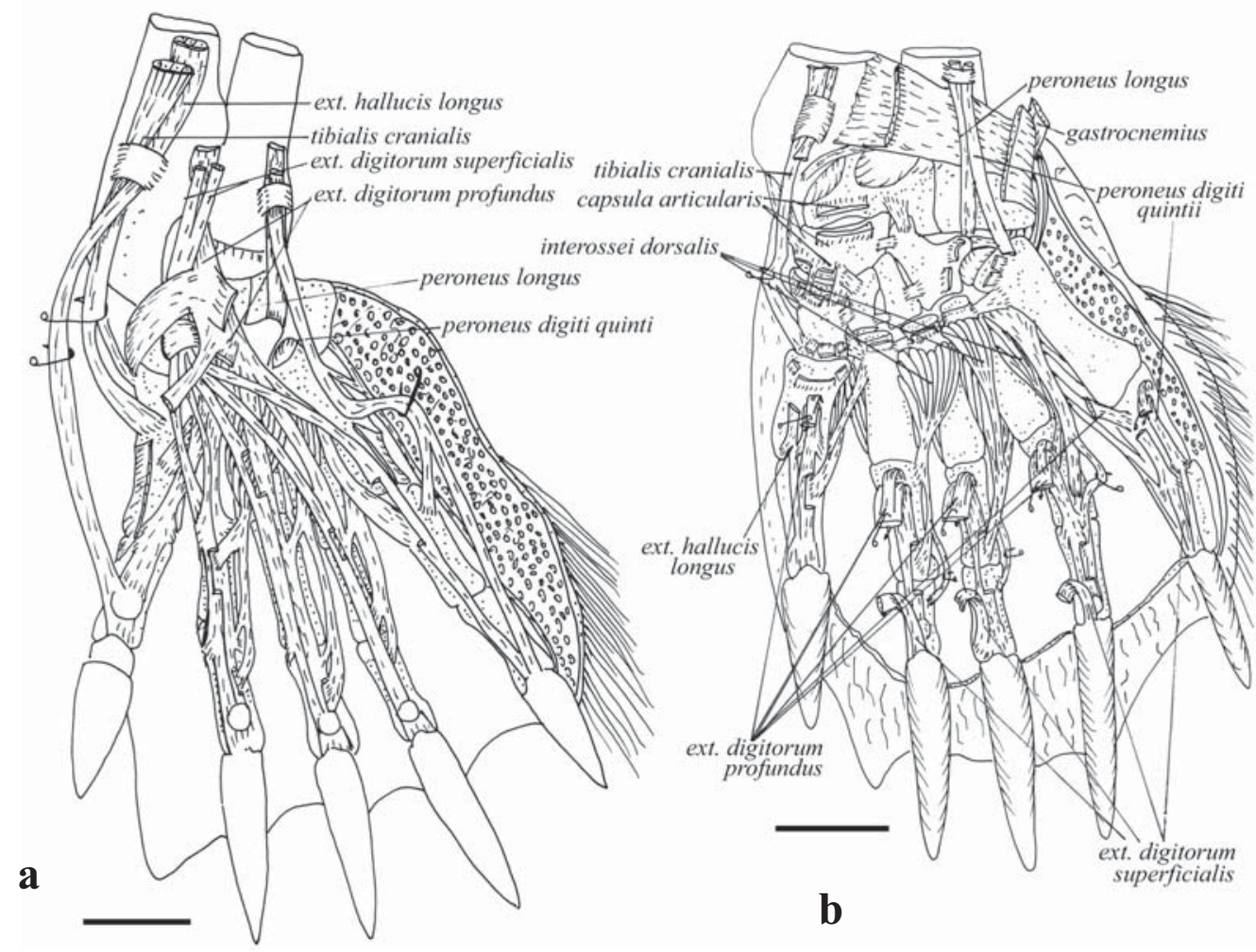

Figure 19. DORSAL VIEW OF TENDONS OF LONG AND SHORT EXTENSORS OF THE FOOT IN ORNITHORHYNCHUS ANATINUS: (a) SUPERFICIAL LAYER; (b) DEEP LAYER. Abbreviation: ext. - extensor. Scale bars $1 \mathrm{~cm}$. 


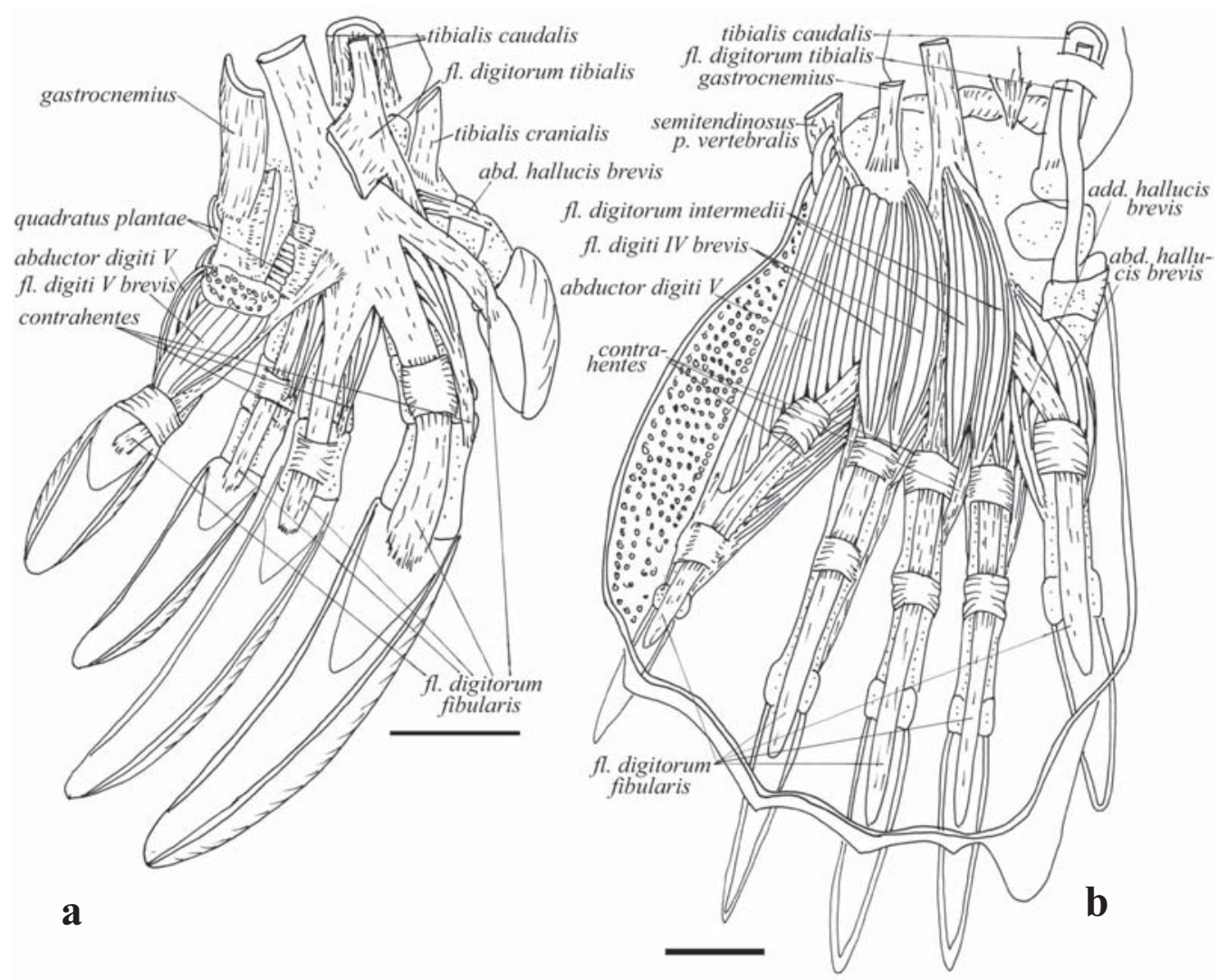

Figure 20. SUPERFICIAL SHORT MUSCLES AND TENDONS OF LONG FLEXORS OF THE FOOT INTACHYGLOSSUS ACULEATUS (a) AND ORNITHORHYNCHUS ANATINUS (b). Abbreviations: abd. — abductor; add. — adductor; fl. — flexor; p. — pars. Scale bars $1 \mathrm{~cm}$.

the place of origin of the $\mathrm{m}$. popliteus, and the fibula where it occupies three-quarters of the bone, being situated lateral to the m. peroneotibialis. At about the level of the distal two-thirds of the shin the caudal surface of $\mathrm{m}$. tibialis caudalis is seen to be covered by a tendinous sheet which is gradually getting thicker and at the level of the ankle joint becomes continuous with a broad flat tendon whose margins are somewhat elevated. There is a synovial sheath of the $\mathrm{m}$. flexor digitorum tibialis on this broader one. The $\mathrm{m}$. tibialis caudalis inserts on the medial tubercle on the plantar surface of the astragalus.

This muscle in Ornithorhynchus (Figs. 14, 16, 17, 20,21 ) arises between the $m$. flexor digitorum fibularis and $\mathrm{m}$. flexor digitorum tibialis on the caudal aspect of the fibula, the origin stretching along the medial edge of the fibula to more than three-fifths of the bone length. The caudal surface of the muscle is concave. About the level of the middle of the shin there appears a tendinous covering on the muscle surface, which at the level of the ankle joint becomes continuous with a broad tendon bearing, as in Tachyglossus, a synovial sheath of the $\mathrm{m}$. flexor digitorum tibialis. Both tendons run below the spur base, that of the $\mathrm{m}$. tibialis caudalis inserting on the distal end of the calcaneus.

M. flexor digitorum tibialis in Tachyglossus (Figs. $14,16-18,20)$ arises on the laterocaudal and lateral aspects of the proximal extremity of the processus parafibularis medial to the $\mathrm{m}$. gastrocnemius lateralis. About the level of the middle of the shin the muscle bundle becomes continuous with a thin flat tendon lying on the surface of the tendon of $\mathrm{m}$. tibialis caudalis in a special groove. Both tendons lie deep to the transverse ligament of the distal extremity of the shin. The m. flexor digitorum tibialis inserts by a broad aponeurosis on the medial edge of the first toe and sends as well tendinous guys to the tuber calcanei, the proximal end of the laterodorsal aspect of the fifth metatarsal, and transverse tendinous ligaments of metatarsal joints of the fourth and fifth toes. The insertion has become broader to fuse with the deeper plate of the aponeurosis plantaris which probably led to that the $m$. flexor digitorum tibialis of the echidna has been mistaken by some authors for the $\mathrm{m}$. plantaris (Mivart, 1866; Westling, 1889).

This muscle origin inOrnithorhynchus (Figs. 14, 16, $17,20)$ is the proximal end of the processus parafibularis between the $\mathrm{m}$. popliteus and $\mathrm{m}$. tibialis caudalis, from where it spreads down to the distal end of the processus articularis fibularis. About the level of the second third of the shin, the flat muscle bundle becomes continuous with a round thin tendon which lies in the synovial sheath anchored on the surface of the tendon of $\mathrm{m}$. tibialis caudalis. It runs to the medial side of the foot and passes 


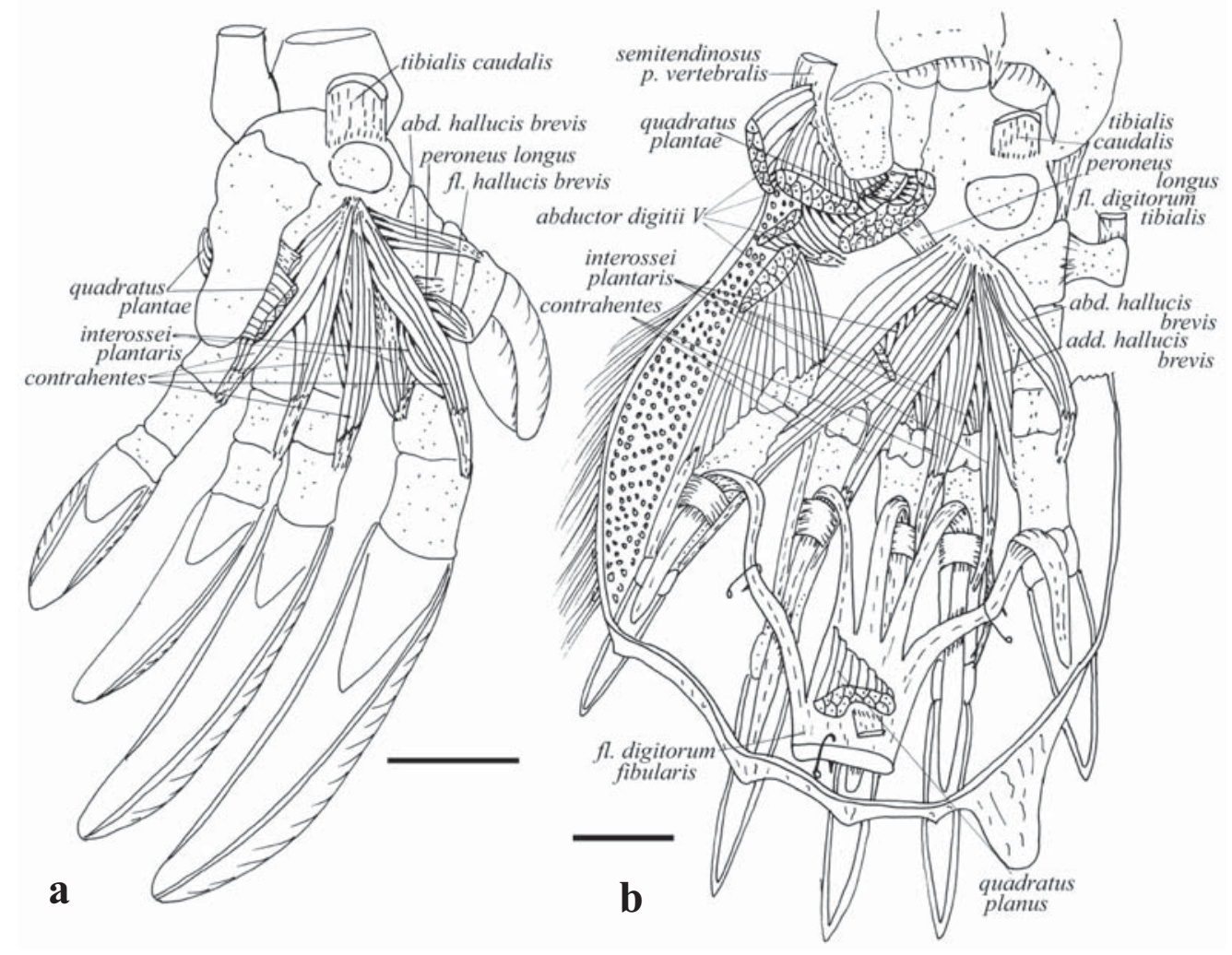

Figure 21. DEEP SHORT MUSCLES OF THE FOOT, THE SECOND LAYER, IN TACHYGLOSSUS ACULEATUS (a) AND ORNITHORHYNCHUS ANATINUS (b). Abbreviations: abd. — abductor; add. — adductor; fl. — flexor. Scale bars $1 \mathrm{~cm}$.

below the spur base to insert by a broadening on the plantar surface of the medial sesamoid which is probably homologous with the praehallucis.

M. flexor digitorum fibularis in Tachyglossus (Figs. 14-18, 20,23). Its origin is the proximal end of the processus parafibularis distal to the $\mathrm{m}$. gastrocnemius lateralis, as well as the lateral edge and more than two-thirds of the cranial surface of the fibula, whereas on the caudal surface of the bone it takes just a narrow stripe. The caudal surface of the bundle for about onehalf of the muscle length is covered by a tendinous sheet which gradually becomes continuous with a flat tendon running along the medial aspect of the tuber calcanei to the foot. At the foot this tendon forms a plate which is split into five tendons running to insert on the ungual phalanges of the toes. On the plantar surface of the toes every tendon passes through a special synovial sheath, these merging the aponeurosis plantaris. The insertion tendon of $\mathrm{m}$. quadratus plantae anchors on the dorsal surface of the tendon running from the plantar surface of the tendinous plate to the fifth toe. The fifth-toe tendon has been described also by Mivart (1886), whereas neither Lewis (1963) nor Jouffroyet al. (1971) mentioned it.

The $\mathrm{m}$. flexor digitorum fibularis in Ornithorhynchus (Figs. 14, 15, 17, 18, 20, 21, 23) arises by an aponeurosis well below the broadening of processus parafibularis and distal to the $\mathrm{m}$. gastrocnemius lateralis. (The aponeurosis then turns into an inner tendinous sheet spreading to one-third of the muscle). Its origin also stretches along the lateral edge of the process, then becomes considerably broader on the fibula occupying the whole of the caudal surface of its proximal part. It is getting narrower when spreading downward to the level of one-half of the bone. Its attachment includes also some of the cranial surface of the fibula, spreading to the distal third of the bone length. From about half way along the muscle the fibres are covered by a tendinous sheet. At the distal third of the shin the latter becomes continuous with a tendon running medial to the plantar eminences of the tuber calcanei, where the tendon becomes much broader. From the tuber calcanei a strong ligament comes to the inner surface of the broadened tendon to keep the latter one in a special deepening on the tuber surface. The short muscles of the hind foot (see below) attach on both the inner and outer surfaces of the broadening. Distally the tendon of $\mathrm{m}$. flexor digitorum fibularis becomes split into five tendons running to the ungual phalanges of all the toes, their synovial sheaths become thicker above the metatarsal joints of the four medial toes and I-II phalanges' joints of the three middle toes. The synovial sheaths become thicker above the sesamoid bones of the toe joints, the ring-shaped ligaments being formed here. 


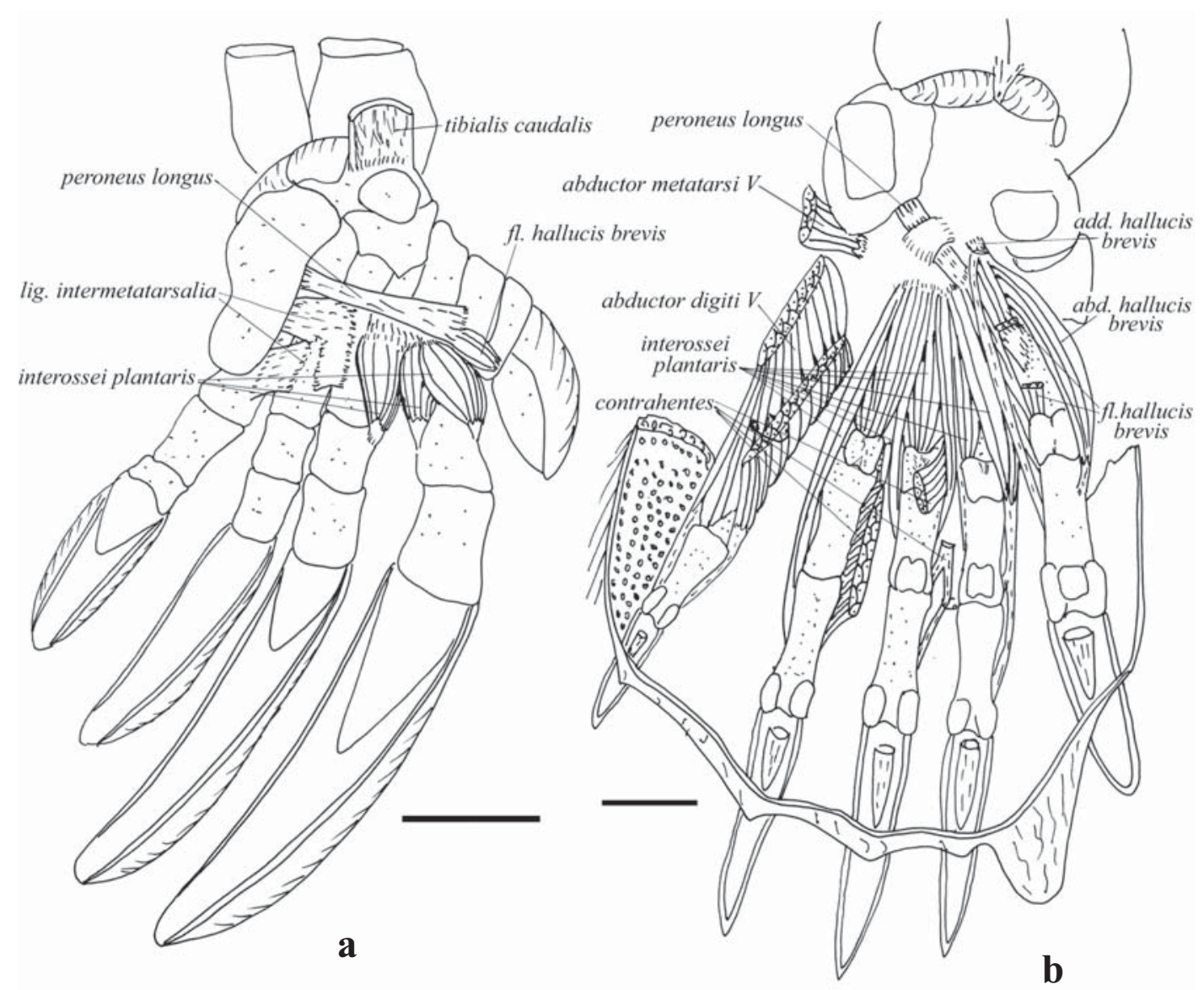

Figure 22. DEEP SHORT MUSCLES OF THE FOOT, THE THIRD LAYER, IN TACHYGLOSSUS ACULEATUS (a) AND ORNITHORHYNCHUS ANATINUS (b). Abbreviations: abd. — abductor; add. — adductor; fl. — flexor; lig. — ligamentum. Scale bars $1 \mathrm{~cm}$.

\section{Short muscles of the hind foot}

Extensor digitorum brevis is lacking in the Monotremata.

Three main groups of the short flexors of the hind foot can be distinguished in Tachyglossus, namely the muscle group which is connected with the tuber calcanei and the two others (the superficial and the deep ones) which originate on the plantar surface of the deep aponeurosus of the sole.

These muscle patterns in Ornithorhynchus are more complex, especially those of the deep group. There are, besides the three main groups mentioned above, two additional muscles in the platypus, which arise from the plantar surface of the insertion tendon of $\mathrm{m}$. flexor digitorum fibularis and which are probably homologous with the $\mathrm{m}$. flexor digitorum brevis intermedii of therian mammals.

In Tachyglossus there are four muscles included into the group connected with the tuber calcanei, namely the $\mathrm{m}$. flexor digiti quinti brevis, $\mathrm{m}$. abductor digiti quinti, m. abductor metatarsi $\mathrm{V}$, and $\mathrm{m}$. quadratus plantae.
Flexor digiti quinti brevis in Tachyglossus (Figs. $17,18,20)$ arises on the distal process of the tuber calcanei and adjacent part of the aponeurosis plantaris, the latter connected with a tendinous broadening which lies at the base of the lateral callosity. The muscle under consideration inserts on the plantar aspect of the broadened distal extremity of the second phalanx of the fifth toe, lateral to the synovial sheath of $m$. flexor digitorum fibularis.

In Ornithorhynchus this muscle is lacking.

M. abductor metatarsi $\mathbf{V}$ was found in the Monotremata. Its origin in Tachyglossus (Fig. 23) is the lateral aspect of the tuber calcanei and the inner surface of the tendinous plate underlying the heel callosity. The insertion is on the lateral side of the distal part of the fifth metatarsal.

In Ornithorhynchus (Figs. 22, 23) the origin of this muscle is a branch of the insertion tendon of $\mathrm{m}$. semitendinosus p. vertebralis and the adjacent edge of the tuber calcanei. The insertion is on the lateral edge of the proximal extremity of the fifth metetarsal.

M. abductor digiti quinti in Tachyglossus (Figs. $18,20,23)$. The origin of this muscle is close to that of 


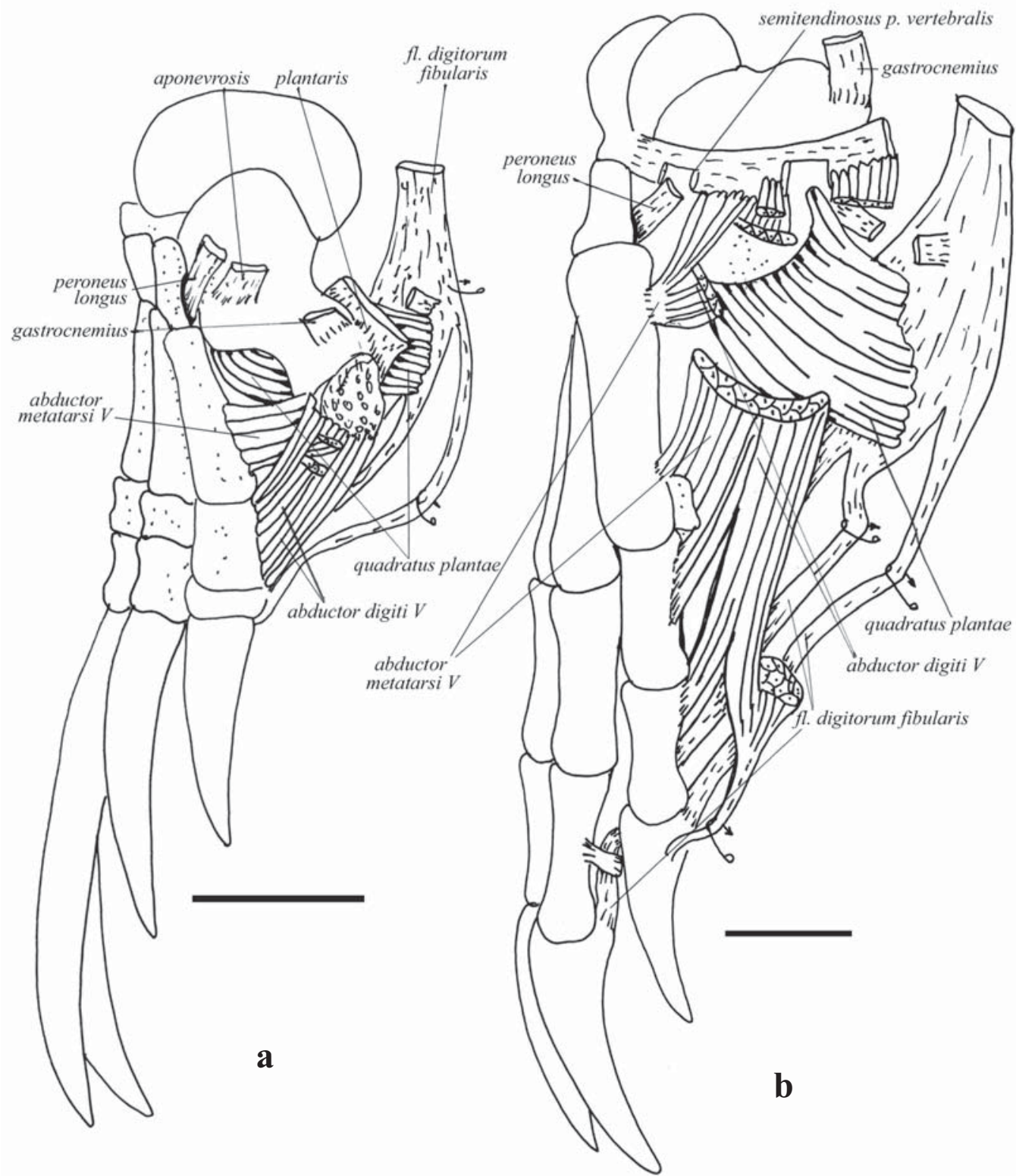

Figure 23. LATERAL VIEW OF SHORT MUSCLES OF THE FOOT IN TACHYGLOSSUS ACULEATUS (a) AND ORNITHORHYNCHUS ANATINUS (b). Abbreviation: fl. - flexor. Scale bars $1 \mathrm{~cm}$.

the $\mathrm{m}$. abductor metatarsi $\mathrm{V}$, on the upper point of the tuber calcanei and the tendinous sheet underlying the heel callosity. The insertion is on the lateral edge of the first phalanx of the fifth toe.

In Ornithorhynchus (Figs. 17, 18, 20-23) this muscle arises from the branch of the insertion tendon of $\mathrm{m}$. semitendinosus p. vertebralis, superficial to the m. abductor metatarsi $\mathrm{V}$, and inserts on the lateral edges of the first and second phalanges of the fifth toe and of the distal extremity of the fifth metatarsal.

M. quadratus plantae $(=\mathrm{m}$. flexor accessorius, according to Lewis, 1989) in Tachyglossus (Figs. 20, 21, 23) arises on the lateral edge of the tuber calcanei proximal to the $\mathrm{m}$. abductor metatarsi $\mathrm{V}$. The muscle bundle is located closer to the plantar surface of the foot than the tubercle. The fibres insert on the plantolateral side of that one of the tendons of $\mathrm{m}$. flexor digitorum fibularis which runs to the fifth toe and then passes deeper to insert on the tendon leading to the fourth toe.

This muscle inOrnithorhynchus (Figs. 21, 23) arises on the distal edge of the dorsal surface of the tuber calcanei and inserts on the dorsal surface of the common tendon of $\mathrm{m}$. flexor digitorum fibularis.

In therian mammals the $\mathrm{m}$. quadratus plantae arises generally, as in the monotremes investigated, on the lateral aspect of the tuber calcanei. But in therians the muscle arises from the plantar surface of the tuber calcanei. It is probably preferable to consider the dorsal surface 
of the tuber calcanei of Monotremata as corresponding with the plantar surface of the tubercle of Theria.

In Ornithorhynchus there are two more muscles which also originate on the tuber calcanei. These are two bundles of the m. flexor digiti quarti brevis (Figs. 17, 20) which insert on the lateral and medial sides of the transverse ligament keeping the insertion tendon of $\mathrm{m}$. flexor digitorum fibularis in the deepening on the tuber calcanei surface (see above).

In Ornithorhynchus there are two muscle bundles originating on the plantar surface of the common tendinous plate of $\mathrm{m}$. flexor digitorum fibularis (Fig. 17, 20) and inserting on the transverse ligaments of the metatarsal joints, that is, on the lateral side of the ligament over the third toe and on the medial side of the ligament over the second toe. Both muscles and the previously described two bundles arising on the tuber calcanei have been reported as the $\mathrm{m}$. flexor brevis digitorum perforatus (Manners-Smith, 1894). In fact, the origin pattern of the bundles of $\mathrm{m}$. flexor digiti quarti brevis is similar with that of the $\mathrm{m}$. flexor digitorum brevis (=flexor perforatus) of some therians. However, the muscles arising from the surface of the common tendon of $\mathrm{m}$. flexor digitorum fibularis can scarcely be homologous with the $\mathrm{m}$. flexor digitorum brevis, and should be named the $\mathrm{m}$. flexor digitorum intermedii (Aristov, 1990).

The group of muscles originating on the surface of the deep aponeurosis of the hind foot is probably homologous with the $\mathrm{m}$. contrahentes of reptiles, as the topography patterns of the muscles mentioned have many similarities with the echidna and reptiles. In reptiles the m. contrahentes arise superficial to (closer to the plantar surface) the $\mathrm{m}$. interossei and insert on the medial sides of the first phalanges of all the toes. In Tachyglossus (Figs, 20, 21) there are four muscles arising on the deep aponeurosis plantaris at the level of the tarsalia III which insert on the medial sides of the second phalanges of the II-V toes.

M. contrahentes in Ornithorhynchus (Figs. 20-22) arise by a common aponeurosis on the plantar tubercle of the naviculare (centrale). From the most superficial layer of the aponeurosis $\mathrm{m}$. contrahentis digiti quinti takes its origin and inserts on the medial sides of the distal extremity of the fifth metatarsal and the first and second phalanges of the fifth toe, extending to the distal end of the latter. The $\mathrm{m}$. contrahentes digiti III et IV arise from the second and third layers of the aponeurosis from where they run to insert medially on the metatarsal bones, the first phalanges and the proximal extremities of the second phalanges of the third and fourth toes. The $\mathrm{m}$. contrahentis of the second toe in the platypus is absent.

M. abductor hallucis brevis in Tachyglossus (Figs. 20,21 ) originates on the medial border of the muscle bundle of $\mathrm{m}$. contrahentis of the second toe and inserts on the medial side of the proximal extremity of the first phalanx of the first toe.

In Ornithorhynchus (Figs. 20-22) the muscle originates by an aponeurosis which is common to that of the $m$. contrahentes and inserts on the medial side of the proximal extremity of the first phalanx of the first toe.
M. flexor hallucis brevis in Tachyglossus (Figs. 21, 22) arises on the plantar surface of the insertion tendon of $\mathrm{m}$. peroneus longus and inserts on the ungual phalanx of the first toe.

In Ornithorhynchus (Fig. 22) the muscle originates beneath the $\mathrm{m}$. adductor hallucis brevis from the common aponeurosis and inserts on the lateral part of the metatarsal sesamoid of the first toe.

M. adductor hallucis brevis in Tachyglossus is lacking.

In Ornithorhynchus (Figs. 20-22) it arises from the common aponeurosis between the origins of the $\mathrm{m}$. abductor hallucis brevis and $\mathrm{m}$. contrahentis of the fourth toe and inserts on the lateral side of the proximal extremity of the first phalanx of the first toe.

The deepest group of the short muscles of the hind foot in the Monotremata (Figs. 21, 22) is represented by the interossei muscles. They are three in Tachyglossus and they arise from a deep aponeurosis at the level of the distal extremities of the tarsalia. The $\mathrm{m}$. interossei insert on the medial side of the proximal extremity of the first phalanx of the third toe, and the medial and lateral sides of the proximal extremity of the first phalanx of the second toe.

The m. interossei of Ornithorhynchus (Figs. 19, 21, 22) are difficult to compare with those of Tachyglossus and therians. We consider the platypus to have three bundles of the $\mathrm{m}$. interossei dorsales (Fig. 19). The $\mathrm{m}$. interosseus dorsalis II arises on the dorsal surface of the third metatarsal and dorsolateral edge of the second metatarsal and inserts on the dorsolateral edges of the proximal and distal extremities of the first phalanx and the proximal extremity of the second phalanx of the second toe. The m. interosseus dorsalis III arises on the dorsal surface of the fourth metatarsal, the insertion pattern on the third toe being the same as that of the previous bundle. The $\mathrm{m}$. interosseus dorsalis IV arises on the dorsolateral surface of the fourth metatarsal and inserts on the dorsal surface of the proximal extremity of the first phalanx of the fourth toe. From the proximal extremities of the fourth and fifth metatarsals a tendon arises, its insertion pattern being the same as those of the insertion tendons of $\mathrm{m}$. interossei dorsales II et III on the fourth toe. In addition to this, from the medial edge of the proximal end of the second metatarsal to the dorsal surface of the first phalanx of the first toe there is a tendon which extends to merge with the insertion tendon of $\mathrm{m}$. adductor hallucis brevis (Fig. 20).

M. interossei plantares are represented by two groups of muscles. The first one consists of four long narrow muscle bands which originate on the plantar surfaces of the tarso-metatarsal joint bursae, the two of them inserting on the lateral surfaces of the second phalanx of the fourth toe and the first phalanx of the third toe, and the other two inserting on the medial surfaces of the first phalanx of the third toe and the first and second phalanges of the second toe (Fig. 22). The second group consists of three broad short muscles which arise on the plantar surfaces of the three middle metatarsal bones and insert on the metatarsal sesamoid bones of the II-IV toes. 
The adductor muscles of therians have been thought to be homologous with the $\mathrm{m}$. contrahentes of reptiles (Ribbing, 1938; Jouffroy \& Lessertisseur, 1959; KyouJouffroy, 1971; and others). But the m. contrahentes should be referred to as a group of short muscles inserting on the medial sides of all the toes. In terrestrial locomotion of animals with widely extended extremities these muscles keep the hind foot from turning laterally during support phase. When gradually the primitive therian extremities become parasagittal in position, the forces disappear which tend to turn the hind foot laterally. To increase the support it is necessary to prevent moving apart toes. The $\mathrm{m}$. contrahentis III disappears and some muscles come to insert on the lateral sides of the first and second toes. The muscles inserting on the fourth and fifth toes are without any doubt homologous with the $\mathrm{m}$. contrahentes of reptiles and monotremates. But the muscles of the same layer inserting on the lateral sides of the first and second toes are most likely derived from the $\mathrm{m}$. interossei. The above description on the complex structure of the $\mathrm{m}$. interossei in the platypus could illustrate a possible transformation of the $\mathrm{m}$. interossei into the $\mathrm{m}$. adductores. This is preferable to us the name $\mathrm{m}$. adductores when dealing with therians, and that of $\mathrm{m}$. contrahentes when discussing reptiles or monotremates.

\section{Hind limb peculiar action in Monotremata}

Hind limb structure in the monotremes is a result of their peculiar locomotion. In both the short-nosed echidnas (Tachyglossus) and the long-nosed echidnas ( $\mathrm{Za}$ glossus) the hind limb specific morphology is a result of burrowing specialization of these animals whereas in the platypus, swimming defines the structure. To analyse platypus hind limb movement we used a film of this animal swimming under water.

Unfortunately, filming did not permit us to form a judgement about the echidna's hind limb action during loosening the ground as the extremities of the burrowing animal would be completely hidden by the body spiny covering. In an emergency echidnas burrow straight down with remarkable speed using both hind and fore feet supplied with strong curved claws so that the animal body is seen to rotate rapidly in different directions around the vertical axis.

To realize how the echidna's limbs and bones move and the muscles function during burrowing we had to use the published data on X-ray filming of the echidna (Jenkins, 1970; Pridmore, 1985).

The different specialisation patterns of the two monotreme species investigated result in differences in their hind limb muscle structure and degree of robustness. To estimate these differences we used relative muscle weight, i.e. the percentage ratio a single muscle weight to the sum weight of all the hind limb muscles, and the muscle robustness expressed by physiological cross-section (Table 1). The data obtained show the influence of the platypus swimming habits upon its hind limb morphology.
The main differences in hind limb movements in the monotreme species are as follows: in the propulsive phase the platypus' femur is directed to the sagittal plane at a larger angle than that of the echidna and, besides, the distal extremity of the femur in the platypus is situated considerably more dorsal to the acetabulum. The platypus' femur moves in such a way as at the end of the propulsive phase to be situated somewhat ventral to a horizontal plane drawn through the acetabulum. The distal extremity of the echidna's femur at the beginning of the propulsive phase is situated a little higher than the acetabulum, and at the end of the phase it finds itself considerably ventral to it. So during terrestrial locomotion the echidna's body raises up noticeably higher above the plane of support than that of the platypus.

It should be mentioned that at the beginning of the propulsive phase the platypus' shin is vertically directed, whereas in the echidna it is inclined cranially and at the end of the phase the knee looks forward. The distal extremity of the shin of the platypus moves to a shorter distance caudally than that of the echidna, so the platypus' shin shows more restricted horizontal mobility than the echidna's.

To realize and estimate the echidna's hind limb action we put the hind extremity skeleton in two such positions, at the beginning and the end of the propulsive phase, based on the published X-ray film data (Jenkins, 1970; Pridmore, 1985). The muscle lengths in both positions were measured, as well as the lever arms of the forces produced by the pelvic joint muscles during retraction, protraction, abduction, adduction, pronation, and supination of the femur, the opposite movements being marked by "+" and "-" signs.

As it can be seen, the gluteal, long and short postfemoral muscles contract during the propulsive phase, all being synergists, and the $\mathrm{m}$. iliopsoas alone as their antagonist.

The m. gluteus superficialis, $m$. gluteus medius and $\mathrm{m}$. pectineus would shorten during the retraction of the femur, they are getting no longer. It means that the main function of these muscles is pronation of the femur in the pelvic joint. As a result of these muscles' exertion in the propulsive phase the femur moves in such a way that both of its condyles change their position from horizontal to a vertical. The hind limb becomes bent in the knee joint, the distal extremity of the shin moving backward relatively to the acetabulum.

The femur of the echidna is flattened and the caput femoris replaced somewhat medially, such a structure promoting larger pronation. So the rotation axis of the femur is situated close to the medial edge of the bone. The flattened form of the femur results in increasing the lever arms of the forces produced by the muscles. Inserting on the lateral edge of the bone (the mm. gluteus medius, gluteus superficialis, caudofemoralis), and decreasing the lever arms and therefore the pronation action of the $\mathrm{m}$. iliopsoas. Pronation is executed also by the adductor muscles inserting on the epicondylus medialis. In the echidna the epicondyle is elongated medially thus increasing the lever arms of the forces produced by the adductors. 


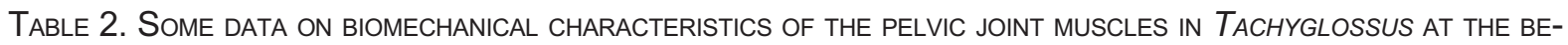
GINNING (b) AND tHE END (e) OF THE PROPUlSIVE PHASE DURING TERRESTRIAL LOCOMOTION. ABbREVIATION: P. - PARS.

\begin{tabular}{|c|c|c|c|c|c|c|c|c|c|}
\hline \multirow{6}{*}{ Muscles } & \multirow{5}{*}{\multicolumn{2}{|c|}{$\begin{array}{l}\text { The muscle } \\
\text { length, } \mathrm{mm}\end{array}$}} & \multirow{6}{*}{$\begin{array}{l}\text { Change of the } \\
\text { muscle length, } \\
\text { i.e. percentage } \\
\text { ratio "e" to "b" }\end{array}$} & \multicolumn{6}{|c|}{ The lever arms of the muscles executing the actions of } \\
\hline & & & & \multirow{2}{*}{\multicolumn{2}{|c|}{$\begin{array}{c}\text { retraction } \\
(+)\end{array}$}} & \multicolumn{2}{|c|}{ abduction } & \multicolumn{2}{|c|}{ pronation } \\
\hline & & & & & & \multicolumn{2}{|c|}{$(+)$} & \multicolumn{2}{|c|}{$(+)$} \\
\hline & & & & \multicolumn{2}{|c|}{ protraction } & \multicolumn{2}{|c|}{ adduction } & \multicolumn{2}{|c|}{ supination } \\
\hline & & & & \multicolumn{2}{|c|}{$(-)$} & \multicolumn{2}{|c|}{$(-)$} & \multicolumn{2}{|c|}{$(-)$} \\
\hline & b & e & & $\mathrm{b}$ & e & $\mathrm{b}$ & e & $\mathrm{b}$ & e \\
\hline iliopsoas, upper border & 35 & 42 & 120 & -6 & -8 & -5 & 0 & -5 & -1 \\
\hline iliopsoas, lower border & 28 & 39 & 139 & -28 & -21 & -22 & -4 & -2 & -2 \\
\hline gluteus superficialis & 58 & 58 & 100 & -2 & -1 & +12 & 0 & +11 & +10 \\
\hline gluteus medius, upper border & 60 & 42 & 70 & -1 & +1 & 0 & +2 & +2 & +17 \\
\hline gluteus medius, middle part & 47 & 32 & 68 & -17 & -16 & +1 & +12 & +1 & +18 \\
\hline gluteus medius, lower border & 41 & 36 & 88 & -27 & -26 & +2 & +5 & +2 & +13 \\
\hline pectineus & 23 & 21 & 91 & -3 & +2 & -10 & -5 & +1 & -1 \\
\hline quadratus femoris & 35 & 32 & 91 & 0 & +1 & +1 & -5 & 0 & -2 \\
\hline adductor brevis & 38 & 37 & 97 & +8 & +8 & 0 & -4 & 0 & 0 \\
\hline adductor magnus & 70 & 62 & 89 & +3 & +19 & -2 & -4 & 0 & +1 \\
\hline adductor longus & 65 & 55 & 85 & +13 & +19 & -17 & -5 & +1 & +1 \\
\hline caudofemoralis & 48 & 48 & 100 & +4 & +3 & +7 & +8 & +10 & +4 \\
\hline semitendinosus $p$. vertebralis & 95 & 88 & 93 & & & & & & \\
\hline semitendinosus $p$. ischiadicus & 87 & 76 & 87 & & & & & & \\
\hline semimembranosus anterior & 73 & 70 & 96 & & & & & & \\
\hline semimembranosus posterior & 80 & 73 & 91 & & & & & & \\
\hline gracilis anterior & 50 & 40 & 80 & & & & & & \\
\hline gracilis posterior & 81 & 72 & 89 & & & & & & \\
\hline biceps femoris & 93 & 78 & 84 & & & & & & \\
\hline
\end{tabular}

It can be seen from the X-ray film showing the platypus swimming (Jenkins, 1970; Pridmore, 1985) that during the propulsive phase the pelvis moves straight forward in a horizontal plane. But when dealing with usual films available to us we noticed that the longitudinal axis of the pelvis would move aside from the sagittal plane. So to estimate the deviation of the pelvic girdle from the support point of the hind foot we used both variants, the first according to which the pelvic girdle is moving straight forward, and the second showing that during the symmetrical gaits at the beginning of the propulsive phase the anterior end of the pelvis longitudinal axis is directed laterally relative to the support point, the direction becoming opposite at the end of propulsion. The deviation of the longitudinal axis has been taken as $10^{\circ}$ in both directions. To measure the angles, the following points of the pelvic girdle have been chosen: the acetabulum, the upper anterior border of the neural spine of the vertebra sacralis I, and the tuber coxae; The upper point of the tuber calcanei has been taken for the support point of the hind foot. The data obtained are given in Table 3.
Deviation of the longitudinal axis of the pelvis from a straight line which is characteristic of symmetrical gaits, results in increasing pace angle and therefore increasing body movements relatively to a support point. According to the film data during terrestrial locomotion the echidna and platypus bend markedly both the anterior and posterior parts of the body.

The platypus feeds mainly on the bottom of freshwater streams or lakes, proceeding to the surface when breathing becomes necessary. According to all the film data at our disposal, when the animal is rising to the surface its feet move backward and forward. The strongest propulsion occurs when the hind limb bent in the knee joint and extended in the ankle joint, and the web unfolded (see detailed description).

Pronation of the femur in the pelvic joint in Tachyglossus is of much importance during terrestrial locomotion, this being therefore in strict connection with greater robustness of such muscles as mm. gluteus superficialis, gluteus medius, caudofemoralis and the peculiar femur morphology. In Ornithorhynchus it is knee joint bend that is of prime importance in swimming. As a result, in 
TABle 3. VARIANTS of ANGULAR DEVIATIONS OF SOME POINTS OF THE PELVIC GIRDLE DURING THE PROPULSIVE PHASE AS MEASURED RELATIVE TO THE TUBER CALCANEI APEX ( $a$ - THE PELVIC GIRDLE MOVES STRAIGHT; $b$ THE LONGITUDINAL AXIS OF THE PELVIC GIRDLE MOVES ABOUT $10^{\circ}$ FROM THE SAGITTAL PLANE).

\begin{tabular}{|l|c|c|c|c|}
\hline \multirow{2}{*}{ Structure } & \multicolumn{4}{|c|}{ Angle value, in degrees } \\
\cline { 2 - 5 } & \multicolumn{2}{|c|}{ Tachyglossus } & \multicolumn{2}{|c|}{ Ornithorhynchus } \\
\cline { 2 - 5 } & $\mathrm{a}$ & $\mathrm{b}$ & $\mathrm{a}$ & $\mathrm{b}$ \\
\hline Acetabulum & 73 & 88 & 52 & 80 \\
\hline upper anterior border of the neural spine of vertebra sacralis I & 46 & 61 & 34 & 63 \\
\hline tuber coxae & 42 & 55 & 25 & 47 \\
\hline
\end{tabular}

Tachyglossus the sum relative weight of the pelvic joint pronators is $17.3 \%$ whereas in Ornithorhynchus it is only $6.4 \%$. But the calculated force (estimated through physiological cross-section of a muscle) which could be produced by the muscles does not show striking difference between the echidna and platypus. The reason is that the platypus weighs more than the echidna; the hind limb weight of Ornithorhynchus is $70 \mathrm{~g}$ and that of Tachyglossus just $30 \mathrm{~g}$.

The force which could be produced in the femur pronation has been calculated by multiplying the lever arm of the force by the force value, the last named estimated through physiological cross-section of the muscle (Table 1). In Tachyglossus the sum force produced by the muscles at the beginning of the propulsive phase was considerably larger than the force during supination, the former being about 3000 dyn. The m. iliopsoas seems not to act at the beginning of the propulsive phase. At the end of the phase the sum pronation force equals to $10700 \mathrm{dyn}$, the supination force reaching only 700 dyn.

Co-exertion of the mm. iliopsoas, gluteus superficialis, gluteus medius and pectineus executing the femur protraction can not counteract retracting influence of all the other muscles. One of the reasons for this is that the $\mathrm{m}$. iliopsoas seems not to act at the beginning of the propulsive phase, it is being stretched by the femur retractors, thus preparing to act in the next phase. The femur retraction during the propulsive phase is only $15^{\circ}$, and the femur pronation neutralizes totally the protraction effect caused by the m. gluteus medius, this being evident from $\mathrm{m}$. gluteus medius shortening during the propulsion. The total protraction force calculated by summarizing is equal to 17000 dyn (it would be 3700 dyn during the retraction), but the actual protraction force is 120 dyn as it is necessary to take into account the force produced by mere the $\mathrm{m}$. pectineus. It is probable that the long postfemoral muscles would also participate in the femur retraction, but it is difficult to calculate lever arms for them as their exertion affects not only the pelvic joint but the knee joint as well.

At the beginning of the propulsive phase the total force produced by muscles during the femur adduction approximates to $9300 \mathrm{dyn}$, the abduction force being only $1100 \mathrm{dyn}$. At the end of the phase the abduction force raises to $3400 \mathrm{dyn}$, the adduction one decreasing to
$41 \mathrm{dyn}$, as the femur adduction finishes at the end of the propulsive phase.

When swimming, at the beginning of the stroke the platypus draws the hind foot aside, the toes bent down and the foot flattened from both sides. The compressed hind foot is drawn forward and under the belly, the hind limb becomes bent in the ankle joint and the foot at the same time turns to face frontally, the last being executed by the $\mathrm{m}$. peroneus longus, its relative weight in the platypus being equal to $2 \%$ whereas that of the echidna reaching only $0.8 \%$ (Table 1 ). Then the foot turns in the opposite direction, this being executed by the $\mathrm{m}$. tibialis cranialis and $\mathrm{m}$. extensor hallucis longus, these muscles are also shown to be more robust in the platypus compared with the echidna (Table 1). At the same time the femur is seen to be protracted and supinated, and the knee to move upward, thus reaching a higher point than the pelvic joint. Such a high position of the knee makes it possible for it to move ventrally without projecting from the musculo-cutaneous body envelope (as would be necessary in case of using the echidna's locomotion pattern) and thus avoid greater water resistance during swimming. The platypus knee shows the same movement pattern both during terrestrial locomotion and swimming, which is thought to be a result of highly developed swimming adaptation of the animal.

In the Monotremata with their widely extended extremities the combination of femur retraction and adduction results in less approach of the knee joint to the sagittal plane than would occur in the case of mere adduction of the femur, the knee approach to the sagittal plane being accompanied by foot rotation in the ankle joint. The lesser femur adduction would direct the knee movement towards the sagittal plane, the lesser would be the necessity of rotation in the ankle joint. The lesser rotation degree is advantageous for better fixation of the joint and necessary for burrowing. At the beginning of the propulsive phase it is more advantageous for the femur to be inclined to the sagittal plane at a lesser angle, as in this case the femur retraction is accompanied by considerable abduction degree thus compensating the femur adduction so necessary for propulsion. To make a stroke during swimming the retraction of the femur is advantageous, considerable lateral abduction being disadvantageous in this case. During terrestrial locomotion the femur of the platypus is inclined to the sagittal plane 
at a larger angle than that of the echidna, this could also be explained by swimming adaptation of the platypus. At the beginning of the propulsive phase during terrestrial locomotion the femur of Ornithorhynchus is inclined to the sagittal plane at $35^{\circ}$, and the femur of Tachyglossus at $60^{\circ}$. For this reason, despite the femur retraction in both species being $15^{\circ}$, in the echidna the femur movements result in lesser degree of rotation in the ankle joint, and in the platypus the retraction degree of the knee and hind foot is larger than in the echidna.

It is probable that both in Tachyglossus and Ornithorhynchus the retraction of the femur can be affected by the long postfemoral muscles. The more important function of these muscles is knee joint flexion which counteracts water resistance during swimming. The more caudal position of the muscles' origins makes it possible for them to execute the femur retraction simultaneously with knee joint flexion. The muscles' origin further extension backward to the caudal vertebrae would be disadvantageous as it would prevent the tail from acting independently in swimming, thus the origin of the $\mathrm{m}$. gracilis posterior in Ornithorhynchus is replaced caudally of the symphysis (Fig. 12). As the topography of the muscle is advantageous for swimming, it became relatively more robust in the platypus than in the echidna (Table 1).

Of the long postfemoral muscles it is the m. semitendinosus p. vertebralis which shows the most striking differences in structure between the two species investigated. This muscle inserts on the shin distal to the other muscles of this group. The m. semitendinosus $\mathrm{p}$. vertebralis fibres originating on the caudal vertebrae and running to the shin have the most vertical direction, so they contribute most of all to counteracting water resistance which tends to extend the knee joint.

The origin of the main part of $\mathrm{m}$. semitendinosus $\mathrm{p}$. vertebralis spreads far forward to the neural spines of the lumbar vertebrae and the tuber coxae. The vector of the force produced by the muscle's exertion is directed obliquely to the knee joint, that is nearly parallel to the shin, and passes close to the pelvic joint. It can be seen that this muscle's exertion has markedly lesser effect both on extension of the knee joint and retraction of the pelvic joint. The $\mathrm{m}$. semitendinosus $\mathrm{p}$. vertebralis inserts on the medial and lateral edges of the hind foot. Exerting the muscle together with water pressure makes the foot surface become concave during swimming. This muscles' function is of considerable importance in swimming, so in the platypus its relative weight is three times as great as that of the echidna (Table 1). During the stroke the distal end of the hind foot moves faster than the proximal one, this resulting in that distal part of the web is bent out despite the $\mathrm{m}$. flexor digitorum fibularis greater robustness. And bending out the distal end of a flipper (or a web) would result in larger propulsive effect (Gambarjan \& Karapetian, 1961).

The hind foot of the platypus is extremely much flexible. During swimming it can be bent and compressed easily in the preparatory phase and unfolded in the propulsive phase. The hind foot of the echidna is to the contrary rigid, as it is necessary in burrowing. As a result, when the animals are on land their feet move in quite different ways. In Ornithorhynchus at the end of the propulsive phase the proximal part of the hind foot is lifted up, the metatarsal joints being hyperextended. In Tachyglossus the whole of the plantar surface of the foot is in contact with substrate from the beginning to the end of the propulsive phase. In animals with widely extended extremities using symmetrical-diagonal gaits forces are produced which tend to turn the hind foot laterocaudally. This would result in reduced propulsive power. To prevent this laterocaudal turn the platypus hyperextends its hind foot and the echidna anchors onto the substrate by its claws. Such different ways to keep the hind foot firmly in necessary position during terrestrial locomotion result in pronounced structural differences in these two species. In Ornithorhynchus the condyloid surface for articulation with the astragalus and calcaneus is block-shaped, whereas in Tachyglossus it is spherical. Spherical form of the articulation makes it possible for the shin to be inclined at any angle to the foot, with no restrictions for rotation in the ankle joint. It is clear that such marked differences in the ankle joint morphology are caused by the specific locomotory adaptations of these animals.

When, in an emergency, the echidna loosens the substrate with its claws, the active rotation of the ankle joint in the horizontal plane is the main movement executed by the hind foot. Then the echidna dips vertically into the loosened ground; when doing this the animal is seen to rotate around the vertical axis now to the left, now to the right. When the animal is loosening the substrate, the plantar surface of the claws of the second and third toes laterally directed, the plantar surface of the claw of the fourth toe makes an angle about $30-40^{\circ}$ with the horizontal plane, and the claw of the fifth toe lies horizontally. The claw of the second toe seems to dip the most deeply into the substrate, the claw of the fifth toe being the nearest to the surface. As the claw of the second toe is the longest one, it encounters the most considerable resistance to the ground. In full agreement with this way of digging the claws of the four lateral toes show the differences in their structure. The medial sides of the claws of the second and third are characterized by larger growth rate, resulting in a somewhat spiral form of these claws, so that near the claw tip the plantar surface looks laterally. The sole plate of these claws consists of a lesser compact tissue, so that the lateral and medial edges of the horny plate hang over the sole plate from both sides. The plantar surface of the claw at the cross-section is seen to be concave, and limited by two sharp cutting edges of the horny plate (Fig. 24), the edges loosening the substrate and the concave surface helping move aside the loosened ground. The flattened claw of the fifth toe is about three times shorter than that of the second one. Its sole plate is equally compact as the horny plate, so at the crosssection it is seen to have a drop-like form with a lateral sharpened edge (Fig. 24). When the echidna walks, the 


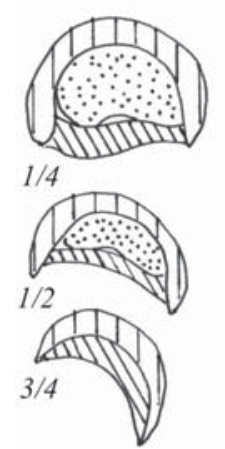

II

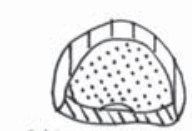

$1 / 4$

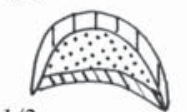

$1 / 2$

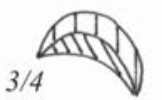

III
Figure 24. CROSS SECTIONS OF THE CLAWS OF TOES II-V IN TACHYGLOSSUS ACULEATUS MADE AT THE SUCCESSIVE LEVELS 1/4, 1/2, AND 3/4 FROM THE PROXIMAL CLAW END. Scale bar $1 \mathrm{~cm}$.

sharp-edged claws cut into the ground and thus prevent the foot from rotating. Such an adaptation results also in greater robustness of the $\mathrm{m}$. tibialis caudalis (Table 1), as this muscle's exertion makes the foot turn thus providing better support.

The echidna's foot is well adapted for burrowing, this being evident also due to some structures restricting mobility of the elements of the foot and thus providing the necessary rigidity. Of these special structures the robust multi-layered aponeurosis plantaris should be mentioned first. Its superficial layer which is directly connected with callosities of the sole inserts on the shin bones, the medial sides of the first metatarsal and the first toe, and the medial side of the tuber calcanei. The superficial layer is fused with the deeper layer. The latter is in fact a continuation of the broadened tendon of the $\mathrm{m}$. flexor digitorum tibialis and inserts on the medial edge of the first phalanx of the first toe and the medial edge of the tuber calcanei. The deeper layer is, in its turn, fused with the deeply submerged common tendinous plate of the $m$. flexor digitorum fibularis. Parallel to the thin bundle of the adductor of the first toe, which lies below the multi-layered aponeurosis, there is a robust ligament running from the plantar tubercle of the tarsalia III to the plantomedial aspect of the ungual phalanx of the first toe. There are tendinous ligaments between the four lateral metatarsalia as well.

Comparative cinematographic analysis of locomotion of some lower tetrapods, therians, and monotremates shows the uniqueness of the latter animals.

In Urodela, Squamates, Sphenodontia and Crocodilia the propulsive phase retraction of the femur is well pronounced, it often reaches $105^{\circ}$ being accompanied by flexion and extension of the knee and ankle joints (Schaeffer, 1941; Snyder, 1952; Gray, 1968; Sukhanov, 1974; and others). In therians the femur retraction is markedly lesser, as a rule. In most artiodactyls it reaches $35-60^{\circ}$ (in giraffe only $23^{\circ}$ ), in elephants $70^{\circ}$, in carnivores $40-65^{\circ}$, in rodents $40-60^{\circ}$ (Gambaryan, 1974). In lower tetrapods the femur pronation and adduction in the pelvic joint is of much lesser importance than in the Monotremata. In therians these functions do not occur in fact during locomotion.

The echidna and platypus walk plantigrade, this together with their widely extended extremities leads to that during the propulsive phase the distal part of the shin moves backward in another way than in therian mammals. In the latter the propulsion of the hind limb is executed by extension of the pelvic, knee, and ankle joints. In the Monotremata flexion of the knee is accompanied by flexion of the ankle joint and pronation in the pelvic joint.

The Monotremata show a pattern between the shin muscles and the tuber calcanei which differs from that of therians. The tuber calcanei in Monotremata is situated lateral to the ankle joint and is in contact with the fifth metatarsal, which resembles the pattern of many cynodonts and morganucodontids (Schaeffer, 1941; Romer, 1956; Jenkins \& Parrington, 1976; and others). The tuber calcanei is the insertion of the shin muscles, so elongation of it in cynodonts promoted abduction force appearing in the ankle joint. As a result, the foot got support from the lateral side, this being advantageous for the animals with widely extended extremities. In the monotremes the tuber calcanei does not project backward and is tightly connected to the fifth metatarsal. The insertion of the shin muscles is more laterally situated to the rotation center of the ankle joint, so exertion of the shin muscles results in abduction of the foot.

The tuber calcanei has been developed not only in Cynodontia and Mammalia, a similar structure can be found in Crocodilia, this being the insertion of the $\mathrm{m}$. gastrocnemius externus. As for the $\mathrm{m}$. gastrocnemius internus, it inserts in crocodiles on the lateral process of the tarsalia $\mathrm{V}$. The presence of the tuber calcanei is rather often considered to be (analogous with mammals) a peculiar adaptation to increase extension of the ankle joint (see, for example, Carroll, 1988). But in our opinion, elongation of the tuber calcanei both in Monotremata and Crocodilia results in increasing abduction of the foot rather than flexion-extension of the ankle joint as the force vector of the shin muscles passes lateral to the vertical axis of the ankle joint. So the tuber calcanei is a structure which is more important for abduction.

In Monotremata, the m. gastrocnemius medialis originates above the medial condyle of the femur, so the muscle's exertion during the support phase prevents the femur from rotation in the pelvic joint. As a result of the m. gastrocnemius lateralis insertion on the processus parafibularis, this muscle's exertion affects only the ankle joint. It executes extension of the ankle joint with a simultaneous turn of the foot especially necessary in swimming. As it has been shown, the relative weight of the muscle in Ornithorhynchus is more than three times greater than in Tachyglossus (Table 1).

In animals using asymmetrical gaits the role of the tuber calcanei is quite different. During symmetrical locomotion the lateral pressure of the foot results in the pelvis longitudinal axis deviation from a straight line, 
thus increasing pace angle. During asymmetrical locomotion such a deviation of the pelvis is absolutely impossible because of both hind limbs' simultaneous propulsion. In the fossil Multituberculata, which had not got achieved yet parasagittal limb position but newertheless had an asymmetrical jumping gait, the role of the tuber calcanei was, so to say, intermediate between those of Theria and Monotremata (Kielan-Jaworowska \& Gambaryan, 1994). As in Monotremata, the calcaneus in Multituberculata is in contact with the fifth metatarsal, and the tuber calcanei is situated obliquely in relation to the longitudinal axis of the foot which, in our opinion, passes along the third metatarsal and the third toe. As a result, the shin muscles' exertion executes abduction of the foot. But in Multituberculata the main function of these muscles is newertheless extension of the ankle joint.

\section{Conclusions}

1. Homologization of the $\mathrm{m}$. gluteus superficialis with the $\mathrm{m}$. piriformis and of the $\mathrm{m}$. semitendinosus $\mathrm{p}$. vertebralis with the m. gluteus maximus is thought to be wrong, as gluteal muscles insert on the trochanter major and labium laterale ossis femoris whereas the $\mathrm{m}$. piriformis which originates on the ventral surface of the processus transversus ossis sacralis inserts as a rule on the upper part of the trochanter major below the $\mathrm{m}$. gluteus medius.

2. Homologization is rejected of the $\mathrm{m}$. peronei digitorum with the $\mathrm{m}$. extensor digitorum superficialis, as the tendons of the latter running to the foot are situated in the interosseous space and not from the lateral side of the fibula.

3. Swimming adaptation in Ornithorhynchus is by all means connected with the necessity of rotating the foot during swimming. It resulted in greater robustness and broader origins of such muscles as the mm. peroneus longus, tibialis cranialis, and extensor hallucis longus which lie deep to the origin of the $\mathrm{m}$. extensor digitorum profundus.

4. The amplitude of vertical shift of the knee in both two species investigated being practically the same, but when the animals walk on land, the platypus' knee joint reaches the higher point and the femur is inclined to the sagittal plane at a larger angle at the early propulsive phase because of Ornithorhynchus swimming adaptation.

5 . The peculiar topography of the $\mathrm{m}$. gracilis posterior in Ornithorhynchus ensures its larger effect on the femur retraction and knee flexion, these functions being of prime importance during swimming. It results in three-time enlargement of the relative weight of the whole muscle and especially of its caudal part in the platypus, as compared with that of the echidna. The $\mathrm{mm}$. semitendinosus p. vertebralis and gastrocnemius lateralis exertion results in the ankle joint extention and the foot broadening thus ensuring the web unfolding and therefore its concave form. The relative weight of these muscles of the platypus is also about three times more than that of the echidna.
6. The condyle surface of the ankle joint is blockshaped in Ornithorhynchus and spherical in Tachyglossus. The block-shaped form of the platypus' condyle helps foot to resist water pressure and not to change trajectory of the stroke movement during swimming, but when the animal walks on land, this results in restriction of movement in the ankle joint. The latter being compensated by mobility of the foot elements one relative to another. The spherical surface of the echidna's ankle condyle ensures all the variability of movements of the foot during walking and burrowing, the relative mobility of the elements inside the foot being minimal.

7. The tuber calcanei origin in higher cynodonts and morganucodontids is connected, as in monotremates, with increasing abduction of the foot in animals with widely extended extremities. When extremities are parasagittal in position, it is extension of the ankle joint during hind limbs' simultaneous propulsion that becomes the main function of the tuber calcanei.

8. The peculiarities of the hind limb functioning during locomotion in the Monotremata are as follows. The femur retraction is no more than $15^{\circ}$, pronation in the pelvic joint reaching a high degree; the knee joint is flexed during the whole of the propulsive phase. In lower tetrapods (Urodela, Squamata, Sphenodontia, Crocodilia) the main propulsive action is executed by the femur retraction which reaches more than $70^{\circ}$, the ankle joint being flexed at the early propulsive phase and extended again to the end of it. The femur pronation and adduction are considerably lesser pronounced in lower tetrapods than in Monotremata. In Theria in the propulsive phase the femur retraction is $35-65^{\circ}$. The ankle and knee joints at the early phase are flexed, and then extended. Adduction and pronation in the pelvic joint are lacking in fact.

ACKNOWLEDGMENTS. We are grateful to A.K. Agadjanian (Paleontological Institute RAS, Moscow) who helped obtain additional material of Monotremata used in this study.

\section{References}

Allen G.M. 1912. Zaglossus // Memoirs of the Museum of Comparative Zoology at Harvard College. Vol.40. P.253307.

Abel W. 1930. Beiträge zur Kenntnis der Anpassungserscheinungen der distalen Hinterfussmuskulatur der Saugetiere bei einem Wechsel der Lebensweise // Morphologisches Jahrbücher. Bd.64. Hf.4. S.558-635.

Appleton A.B. 1928. The muscles and nerves of the post-axial region of the tetrapod thigh// Journal of Anatomy. Vol.62. Pt.2. P.364-438.

Aristov A.A. 1990. [Short muscles of the foot in family Muridae (Rodentia) and homology and nomenclature of these muscles] // Trudy Zoologicheskogo Instituta AN SSSR. Vol.215. P.82-99 [in Russian].

Carroll R.L. 1988. Vertebrate Paleontology and Evolution. New York: W.H. Freeman and Co. 698 p.

Coues E. 1870. On the myology of Ornithorhynchus // Proceedings of the Essex Institute. Vol.6. P.127-173.

Dobson G.E. 1882. A Monograph of the Insectivora, System- 
atics and Anatomy. London: P.I. John Van Voorst. 172 p.

Elftman Y.O. 1929. Functional adaptations of the pelvis in marsupials // Bulletin of the American Museum of Natural History. Vol.58. P.189-232.

Forster A. 1918. Zur Morphogenese der Inscriptio tendinea des M. semitendinosus // Anatomischer Anzeiger. Bd.51. No.7. S.145-164.

Gambaryan P.P. 1960. [Adaptive Features of the Locomotory Organs in Fossorial Mammals]. Erevan: Izdatel'stvo AN Armyanskoi SSR. 195 p. [in Russian].

Gambaryan P.P. 1974. How Mammals Run. New York: Wiley. 367 p.

Gambarjan P.P. \& Karapetjan W.S. 1961. Besonderheiten im Bau des Seenlowen (Eumetopias), der Baikalrobbe (Phoca) und des Seeotters (Enchydra lutris) in Anpassung an die Fortbewegung im Wasser // Zoologische Jahrbücher. Abteilung für Anatomie und Ontogenie der Thiere. Bd.79. Hf.1. S.123-148.

Glaesmer E. 1910. Die Beugenmuskeln am Unterschenkel und Fuss bei den Marsupialia, Insectivora, Edentata, Prosimiae und Simiae // Morphologischer Jahrbücher. Bd.41. Hf.2. S.149-336.

Gray J. 1968. Animal Locomotion. London: Weidenfeld \& Nicolson. 479 p.

Haines R.W. 1939. A consideration of the muscular nerve supply // Journal of Anatomy. Vol.70. No.1. P.33-55.

Howell A. B. 1926. Anatomy of the Wood Rat. Monographs of the American Society of Mammalogists 1.225 p.

Howell A.B. 1933. The saltatorial rodent Dipodomys: the functional and comparative anatomy of its muscular and osseous systems // Proceedings of the American Academy of Arts and Sciences. Vol.67. No.10. P.377-536.

Jenkins F.A., Jr. 1970. Limb movements in a monotreme (Tachyglossus aculeatus): a cineradiographic analysis // Science. Vol.168. No.3938. P.1473-1475.

Jenkins F.A., Jr. \& Parington F.R. 1976. Postcranial skeleton of the Triassic mammals Eozostrodon, Megazostrodon and Erythrotherium // Philosophical Transactions of the Royal Society of London, Series B. Vol.273. No.926. P.387-431.

Jouffroy F.K. 1962. La musculature des membres chez les Lemuriens de Madagascar. Etude descriptive de comparative // Mammalia. T.26. Suppl.2. 340 p.

Jouffroy F.K., Lessertisseur J. \& Saban R. 1971. Particuliarites musculaires des monotremes // Traité de Zoologie. T.16. Fasc.3. Paris: Masson et C. editors. P.679-836.

Kielan-Jaworowska Z. \& Gambaryan P.P. 1994. Postcranial anatomy and habits of Asian multituberculate mammals // Fossils and Strata. No.36. 92 p.

Klingener D. 1964. The comparative myology of four dipodoid rodents (genera Zapus, Napaeozapus, Sicista and Jaculus) // Miscellaneous Publications of the Museum of Zoology, University of Michigan. Vol.93. P.1-100.

Kyou-Jouffroy F. 1971. Musculature des membres // Traité de Zoologie. T.16. Fasc.3. Paris: Masson et C. editors. P.1-476.

Lewis O.J. 1963. The monotreme cruro-pedal flexor muscu- latare // Journal of Anatomy. Vol.97. Pt.1. P.55-63.

Lewis O.J. 1964. The evolution of the long flexor muscles of the leg and foot // International Review of General and Experimental Zoology. Vol.1. P.165-185.

Lewis O.J. 1989. Functional Morphology of the Evolving Hand and Foot. Oxford: Clarendon. 359 p.

Low J.W. 1929. Contributions to the development of the pelvic girdle. III. The pelvic girdle and its related musculature in Monotremes // Proceedings of the Zoological Society of London. Vol.1. Pt.2. P.245-266.

Manners-Smith B.A. 1894. On some points in the anatomy of Ornithorhynchus paradoxus // Proceedings of the Zoological Society of London. P.694-722.

Meckel J.F. 1826. Ornithorhynchi paradoxi Descriptio Anatomica. Lipsiae: G.Fleischer. 63 p.

Mivart S.G. 1866. On some points in the anatomy of Echydna hystrix // Transactions of the Linnean Society of London. Vol.25. Pt.3. P.379-403.

Pearson H.S. 1926. Pelvic and thigh muscles of Ornithorhynchus // Journal of Anatomy. Vol.60. No.1. P.152-163.

Pridmore P.A. 1985. Terrestrial locomotion in Monotremes (Mammalia: Monotremata) // Journal of Zoology London, Series A. Vol.205. Pt.1. P.53-73.

Ribbing L. 1938. Die Muskeln und Nerven der Extremitäten // Bolk L., Goppert E., Kallius E. \& Lubosch W. (eds.). Handbuch der Vergleichenden Anatomie der Wirbeltiere. Berlin \& Wien: Urban \& Schwarzenberg. 1106 p.

Rinker G.C. 1954. The comparative myology of the mammalian genera Sigmodon, Oryzomys, Neotoma and Peromyscus (Cricetinae) with remarks on intergeneric relationships // Miscellaneous Publications of the Museum of Zoology, University of Michigan. Vol.83. P.1-124.

Romer A.S. 1956. Osteology of the Reptiles. Chicago: The University of Chicago Press. $772 \mathrm{p}$.

Schaeffer B. 1941. The morphological and functional evolution of the tarsus in amphibians and reptiles // Bulletin of the American Museum of Natural History. Vol.78. P.395-472.

Schaller O. (ed.). 1992. Illustrated Veterinary Anatomical Nomeclature. Stuttgart: Ferdinand Enke. 614 p.

Snyder R.C. 1952. Quadrupedal and bipedal locomotion of the lizards // Copeia. No.2. P.64-70.

Sukhanov V.B. 1974. Symmetrical Locomotion of Terrestrial Vertebrates and Some Features of Movement of Lower Tetrapods. New Delhi, Bombay, Calcutta, New York: Amerind publishing Co. $274 \mathrm{p}$.

Szalay F.S. 1993. Pedal evolution of mammals in the Mesozoic // Szalay F.S., Novacek M.J. \& McKenna M.C. (eds.). Mammalian Phylogeny: Mesozoic Differentiation, Multituberculates, Monotremes, Early Therians and Marsupials. New York: Springer-Verlag. P.108-128.

Walter L.R. 1988. Appendicular musculature in the echidna, Tachyglossus aculeatus (Monotremata: Tachyglossidae) // Australian Journal of Zoology. Vol.36. No.1. P.65-81.

Westling C. 1889. Anatomische Untersuchungen über Echidna // Bihang till Kongl. Svenska Vetenscaps Akademiens Handllingar. Bd.15. No.3. 171 p. 